\section{Research Square}

Preprints are preliminary reports that have not undergone peer review.

They should not be considered conclusive, used to inform clinical practice, or referenced by the media as validated information.

\title{
Identification of Combination Drug Interaction With Selected Targets of Globlastoma Multiforme Based on Drug Properties and Complex Energy of Docked Complex: a New Approach in Docking Study
}

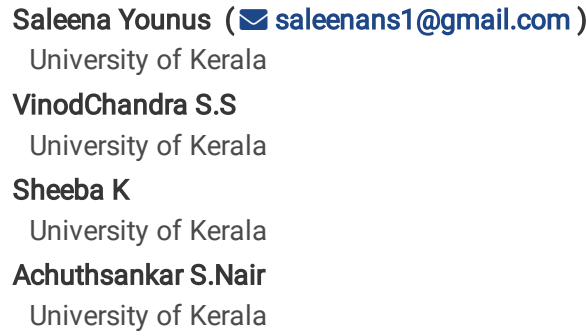

Research Article

Keywords: Combination drug, RTKs, Alkylating agent, Target therapy, Chemotherapy, GlioblastomaMultiforme

Posted Date: January 24th, 2022

DOI: https://doi.org/10.21203/rs.3.rs-1270773/v1

License: (c) (1) This work is licensed under a Creative Commons Attribution 4.0 International License. Read Full License 


\begin{abstract}
Combination drug treatments are frequently used in many diseases, including cancers and AIDS. The main aims of these treatments are to reduce toxicity and improve drug efficacy by inhibiting the activity of a specific target or groups of targets in a cell. The net effect of combination drug efficacy is mainly quantified and interpreted by various terminologies like synergy, additive, agonism, and antagonism based on drugs dose ratio. In single or combination drug treatment, drug action occurs on cells due to the intermolecular level interaction of drugs with protein/DNA/RNA/Enzyme. This type of inter-molecular level interaction can be detected with the help of docking software. However, in the case of combination drug treatments, it is very challenging to identify the multiple drug interaction on each protein with docking score and binding energy. So the proposed work does not follow the classical approach of docking study to predicting the result based on docking score and binding energy. Here we consider drug properties and complex energy of the multiple drug binded complexes for predicting the result. Based on this study, we identified the intermolecular level interaction of synergistic effect showed drugs Crizotinib and Temozolomide in C-MET, C-ROS1, and ALK targets of Glioblastoma Multiforme(GBM) and identified the most stable drug complexes by MD simulation.
\end{abstract}

\title{
Introduction
}

Glioma is a type of brain tumor developed by glial cells or Neuroglial cells. WHO has categorized gliomas into grade I to IV, in which Grade IV is known as Glioblastoma or Glioblastoma Multiforme(GBM). GBM is considered the most malignant brain tumor ${ }^{[1]}$. Genetic disorders and ionization factors are the main risk factors of $\mathrm{GBM}^{[2]}$. It is usually found in the frontal, temporal, parietal, and occipital lobe, often located in the cerebellum, and is rare in the spinal cord. In the adult, more than $60 \%$ of brain tumors come under the category of GBM. The maximum survival rate of GBM is 14.6 months, thus why new drug development is critical in $\mathrm{GBM}^{[1,2,3]}$. The primary treatment of GBM includes surgery, radiotherapy, and chemotherapy ${ }^{[4,5]}$. However, drug resistance has frequently developed in GBM patients during chemotherapy, so the prediction of drug response of GBM patients is a significant challenge. The main reason of drug resistance in GBM patients is the co-activation of several functionally linked receptor tyrosine kinases (RTKs), including C-MET (hepatocyte growth factor receptor),C-ROS1 oncogene (ROS1: RTK class orphan), and Anaplastic Lymphoma Kinase (ALK). Thus, the signal redundancy occurs in GBM patients, and that causes drug resistance and poor prognosis effect in treatment. So, target-based treatment is essential in GBM ${ }^{[6,7]}$. The standard chemotherapy drug used in the treatment of GBM is Crizotinib. It is a multi-targeted chemotherapy drug used in NSCLC and GBM ${ }^{[8,9,10,11]}$. However, due to the co-activation of C-MET, CROS1, and ALK targets, the prognosis effect of Crizotinib is often unpredictable in GBM patients. To overcome the poor prognosis effect, Crizotinib usually combines with other chemotherapy drugs and has been used as a combination drug in $\mathrm{GBM}^{[6,12,13,14]}$. The main aims of such combination drugs are to achieve synergistic therapeutic effect, dose and toxicity reduction, and minimize or delay drug resistance induction and produce better results against diseases ${ }^{[15,16]}$. The drug effecacy of these combination drugs usually be identified by cytotoxic effect ${ }^{[17]}$ based on drug dose ratio, and which is quantified and interpreted by various terminonology like synergy, additive, agosim and antagonism ${ }^{[18]}$. In a cell, the cytotoxic effect occurs due to the result of intermolecular interaction between drugs with macromolecules (DNA/RNA/PROTEINS/ENZYMES)[19]. So understanding the intermolecular interaction of drugs with macromolecule studies is most important. The intermolecular interactions of drug and macromolecule can be identified with docking Softwares ${ }^{[20]}$. However, in the case of combinations drugs, it will be a very challenging process. Because when we apply a combination drug in a particular disease, the combined drug will bind on various sites of single or multiple targets based on its drug properties. Moreover, the desired effect produced by the drug molecules in a diseased pathway always depends on the energy attained the protein structure after when the drug molecules binded on the protein structure. Usually, in docking studies, the potency or effectiveness of drug molecules in a target protein is evaluated by docking score or binding energies ${ }^{[20]}$. But in the case combination drug docking, we cannot predict the result based on docking score and binding energy. Because here the binding of two drugs on a particular target always depend on its overall energy of the docked complex. When one molecule bind on a particular protein surface, the complex attained a least energy. In that energy level, a second molecule can bind on the protein surface. So if we consider a docked complex with good docking score and binding energy, sometimes the overall energy of the docked complex may be very high. In such situations, the docked complex may not be stable, and the drug cannot produce the desired drug effect in diseases ${ }^{[21]}$. So in the proposed work, we focused on the drug properties and least complex energy of the docked complex rather than considering its docking score and binding energy.

In the current study, we try to determine the inter-molecular level interaction of combination drug Crizotinib and Temozolomide in C-MET, C-ROS1, ALK targets, which are considered the primary drug resistance factors in GBM. The dose level analysis studies of these targets proteins with the combination drug Crizotinib and Temozolomide showed a synergistic effect in GBM ${ }^{[6]}$. But the intermolecular level interaction study of these combination drug with C-MET, CROS1, and ALK were not reported so far. The molecular-level interaction of Crizotinib with C-MET, C-ROS1, and ALK target proteins has already been reported by X-Ray Crystallographic studies ${ }^{[22,23]}$ and not in the case of Temozolomide drug. But the insilico studies of individual interaction of both the drugs in targets proteins (C-MET, C-ROS1, and ALK) have also been reported based on drug properties and complex energy. In this study, the result was predicted based on drug properties and least energy of the docked complex rather than using docking score and binding energy of the drugs ${ }^{[21]}$. From the result, the best docked complex was selected on the basis of MD simulation in pico second. The reason for choosing pico second is that, it is not a study of single compound, which is a study of combination drug docked complex. So if we run MD simulation in nano second for each multiple drug binded complex, it will take more memory and time and also waiting months to year completing all these work. That's why we preferred pico second in MD run.

\section{Results}

\section{Docking of Crizotinib and Temozolomide drug with C-MET, C-ROS1, and ALK protein by various Docking methods(forward and reverse docking of drug with proteins).}

\section{1. a). Docking of Crizotinib and Temozolomide drug with C-MET protein (Forward drug docking).}


From the docking of Crizotinib drug with C-Met protein by various docking methods, a total of 353 drug poses had generated. In which we selected the bestdocked complex structure with good druggable binding sites and complex energy were, PDB(P6), RC(S2,P4), DIRECT(P2). In Motif based, we could not identify the druggable binding sites. Based on these three different docking complexes, we again performed protein preparation and also identified the active site for each Crizotinib bounded protein complexes. Then Temozolomide drug docked on each of these binding sites of Crizotinib bounded complexes by four different docking method. In this docking, a total of 77 drug poses of Temozolomide drug were generated and docked on PDB, RC, and DIRECT method of Crizotinib bounded C-MET protein structure .

\section{b). Docking of Temozolomide and Crizotinib drug with C-MET protein(Reverse drug docking).}

Docking of Temozolomide drug with C-MET protein, a total of 134 drug poses had generated and docked with C-MET protein by four different active site identification method. From this docking we selected best complexes of each of the method with drug pose number were PDB(P4), RC (S1, P4), DIRECT(P4) and MOTIF(P1). Then we docked second drug Crizotinib on each of the protein complexes followed by protein preparation and active site identification method. From this docking, 507 drug poses of Crizotinib drug were generated and docked on each Temozolomide drug bounded complexes of C-MET protein via four different docking methods.

\section{2. a). Docking of Crizotinib and Temozolomide with C-ROS1 protein (Forward drug docking)}

Docking of Crizotinib drug with the protein C-ROS1, 259 drug poses were generated and docked by four docking methods From this docking we selected least energy and good druggable binding site complexes were PDB(P6), RC(S4, P4), DIRECT(P3), and MOTIF(P1). Based on this complex, we performed a second docking with Temozolomide drug followed by protein preparation and active site identification. In this docking, 375 Temozolomide drug poses were generated and docked on each of the Crizotinib bounded complexes of C-ROS1 protein by four different docking methods.

\section{2. b). Docking of Temozolomide and Crizotinib with C-MET protein(Reverse drug docking)}

Docking of Temozolomide drug with C-ROS1 protein, a total of 167 drug poses were generated docked in the protein structure by four different docking methods. From this docking, we selected good drug pose with the least energy complexes of Temozolomide drug with C-ROS1 protein structure were PDB (P4), RC (S1 (P4)), DIRECT (P6), and MOTIF (P1). Based on this Temozolomide bounded protein complexes, we performed the second docking of Crizotinib drug followed by protein preparation and four active site identification method in Temozolomide bounded protein complexes. From this docking a total of 238 drug poses of Crizotinib were generated and docked on the Temozolomide drug bounded C-ROS1 protein complex by four different docking method.

\section{3. a). Docking of Crizotinib and Temozolomide drug with ALK protein(Forward drug docking).}

In this docking, a total of 388 drug poses of Crizotinib drug were generated and docked on the

ALK protein by four different active site identification method. In this docking, we selected good drug pose with least energy complexes were, PDB(P10), RC(S1(P8)), DIRECT(P1) and MOTIF(P9). Based on these four Crizotinib bounded protein complexes, the second drug Temozolomide, docked on each of the Crizotinib bounded protein complexes by four different active site identification methods followed by protein preparation and active site identification method. In the second drug docking, a total of 79 drug poses of Temozolomide drug were generated and docked on PDB(P10), RC(S1(P8)), DIRECT(P1) and MOTIF(P9) by four different active site identification method docking.

\section{3. b). Docking of Temozolomide and Crizotinib with ALK protein (Reverse drug docking)}

Docking of Temozolomide drug with ALK protein, 99 drug poses were generated and docked by various docking methods. In this docking, we selected the least energy Temozolomide bounded complexes of ALK protein from four different methods were PDB (P10), RC (S1 (P8)), DIRECT (P1), and MOTIF (P9). Again we docked the Crizotinib drug on the Temozolomide bounded protein structures by four different docking methods followed by protein preparation and active site identification method. In this docking, a total of 1066 poses of Crizotinib drug were generated and docked on the active site of PDB (P10), RC (S1 (P8)), DIRECT (P1), and MOTIF (P9) complexes of ALK protein by four different docking methods. All the drug docking details, docking method, binding site, the total drug poses generated, drug pose docked on the binding sites, and druggable binding sites are mentioned in the supplementary file S1. This supplementary file S1 also included the docking score, binding energy, complex energy of the docked complex, and the primary hydrogen bond interaction showed amino acid residues at each single and multiple drug-protein complex's binding sites. Based on the drug property and least energy, we selected the least energy showed combination drug bounded complexes of forward and reverse docking from each docking, which are shown in the Table1.

\section{SIMULATION analysis result}

In the MD simulation analysis study of least energy docked complexes of combination drug Crizotinib and Temozolomide with C-MET, C-ROS1 and ALK protein complexes, first, we consider the combination drug complexes were $2 \mathrm{WGJ}(\mathrm{PDB}(\mathrm{P6})<-\mathrm{RC}(\mathrm{S} 3, \mathrm{P} 4))$,2WGJ(DIRECT(P2)<-RC(S1, P5)) and (2WGJ(RC(S2, $\mathrm{P} 4)<-(\mathrm{RC} .(\mathrm{S} 3, \mathrm{P} 7))$. But these complexes show instability in hydrogen bonding during MD simulation. So we considered the next least energy showed complex 2WGJ(PDB(P6)<-PDB (P1)) This complex showed strong hydrogen bond interaction on the binding site of the protein during the MD simulation run. In this complex, the pose number, six of the Crizotinib and pose number one of the Temozolomide drug were showed strong hydrogen bond interaction with 
the amino acid residues PR01158 and MET1160 (PDB(P6)), ASN1167(PDB(P1)) at the binding site of 2WGJ protein. The least complex energy of this docked complex was -11252.7717 .

Next we consider the least energy showed complex was the PDB(P6)<-PDB(P4) of 3ZBF protein. This combination drug complex attained the least energy $(-11629.573)$ via when the drug pose number six of the Crizotinib and pose number four of the Temozolomide drugs were bounded on the amino acids were GLU2027, MET2029, ASP2033(Crizotinib), ARG2083, ASP2102,GLY1954(Temozolomide). After the MD simulation run, we could identify that both the drug binded on the active site were strong.

Based on the least energy we considered the combination complex (RC(S1, P8)<-PDB(P2)) of 2XP2 protein. The least energy attained this combination drug complex via when the drug pose number eight of the Crizotinib drug binded on the first site(RC(S1, P8)) of the protein 2XP2(ALK) via RC method and pose number two of the Temozolomide drug binded on the Crizotinib bounded docked complex of 2XP2(RC(S1,P8)) by PDB method (PDB(P2)). The least energy of this docked complex was -11809.0509. After MD simulation, we could understand that the critical amino acid residues MET1199, GLU 1197 interacted with the Crizotinib drug, and the Temozolomide drug interacted with LYS1150 amino acid residues of the 2XP2 protein were strong. Apart from this interaction, some other interactions were identified, which are listed in the Structural analysis Table 3. The results of MD simulation analysis are listed in Table 2. Based on the standard dynamic cascade run, we analyze the protein complex's trajectory by using the analyze trajectory tool of Discovery studio to calculate the RMSD and RMSF of this docked complex.

In the MD simulation run, we consider ligand-free protein, Crizotinib bounded protein complex, and Crizotinib and Temozolomide bounded protein structure of C-MET, C-ROS1, and ALK for understand the structural and conformational changes occurred in the protein structure when multiple drugs binded on the proteins. In the MD simulation, we got the average potential energy to C-MET, C-ROS1, and ALK free protein structure were $-65303,-94171$, and -78997, 2WGJ (PDB (P6), 3ZBF(PDB(P6)), and 2XP2(RC(S1, P8)) were -65903.3,-94428.5, and -78562.8. In the combination drug complexes, 2WGJ(PDB(P6)<$\mathrm{PDB}(\mathrm{P} 1)), 3 Z B F(\mathrm{PDB}(\mathrm{P} 6)<-(\mathrm{PDB}(\mathrm{P} 4))$ and $2 \mathrm{XP} 2(\mathrm{RC}(\mathrm{S} 1, \mathrm{P} 8)<-\mathrm{PDB}(\mathrm{P} 2))$, we got the average potential energy of each of them were $-66150.5,-94690$ and -78575.1 respectively.

\section{RMSD, RMSF Value analysis C-MET,C-ROS1 and ALK protein}

The Analyze trajectory tool generates 100 conformations for each protein structure based on a 224ps time interval. Based on this we generated RMSD and RMSF graph of combination drug complexes of C-MET,C-ROS1 and ALK complexes, which is mentioned in the Figure1 and 2. From this conformations, we can understand structural deviations ${ }^{[24]}$ and the optimized state of the free protein structure and also when a single and multiple ligands bounded on its active site of the proteins. An RMSD value of an optimized protein structure should be less than $1.5 \mathrm{~A}^{\circ}$, which is considered a good structure. From the analysis study of 2WGJ free protein structure, Crizotinib bounded protein structure, and Crizotinib and Temozolomide protein structure, we could identify each protein structure went through how much structural deviations. From the graph of RMSD values of 2WGJ protein structure, all the three structures showed different RMSD values until 130ps; however, all the values went through below the allowed range. From the time 130ps, the free protein structure of $2 \mathrm{WGJ}$ and Crizotinib bounded 2WGJ protein docked complexes (2WGJ (PDB (P6)) went through the values between 1 and $1.2 \mathrm{~A}^{\circ}$. However, the RMSD of Crizotinib and Temozolomide bounded protein complex showed the value between 1 and .8 until $212 p s$. After that, all the three protein structures showed an optimized stage throughout the remaining time. The average RMSD value of free protein structure, Crizotinib bounded protein and Crizotinib and Temozolomide bounded protein structure were $0.966915,1.05556$ and .813927 , respectively.

In the case of 3ZBF protein structure, the RMSD value of ligand-free protein, Crizotinib bounded protein structure, and Crizotinib and Temozolomide protein structures were gone below $1.5 \mathrm{~A}^{\circ}$ till the time $104 \mathrm{ps}$. After that, the ligand-free protein structure and Crizotinib bounded protein structure values came in between 1.2 and $.8 \mathrm{~A}^{\circ}$. But the RMSD values of Crizotinib and Temozolomide bounded protein complex showed in between 1.4 and 1.6 till the time104 and then after the RMSD value of this complex moved through $1.4 \mathrm{~A}^{\circ}$ until $224 \mathrm{ps}$. The Average RMSD values of ligand-free protein, Crizotinib bounded protein, and Crizotinib and Temozolomide bounded protein structures of 3ZBF were 0.996956, 1.12523, and 1.19434.

From the RMSD graph of ALK protein structures, we could identify that the RMSD values of Crizotinib and Temozolomide bounded protein complex showed variations. Sometimes the values of this complex reached above $1.5 \mathrm{~A}^{\circ}$; however, at certain times, it maintained the optimized conformation. Since the time $146 \mathrm{ps}$, ligand-free protein, Crizotinib bounded protein structure, and Crizotinib and Temozolomide bounded protein structures were reached the RMSD value $1.2 \mathrm{~A}^{\circ}$. And also all the structures maintained an optimized state from this region, and RMSD values came in between 1.2 and $1.4 \mathrm{Ao}$ till they reached $224 \mathrm{ps}$. The average RMSD values of ligand-free protein, Crizotinib bounded protein structure, and Crizotinib and Temozolomide bounded protein structures were $1.22515,1.22941$, and 1.34772 respectively.

RMSF value is usually used to measure the ratio of overall fluctuations that occurred in the protein structure ${ }^{[25,26]}$. The fluctuations occurred in a protein structure by the movements in the amino acid residues when the drug molecule bounded on the active site. Usually, the terminal and loop region residues have more chances to fluctuations. The acceptable range of overall fluctuations in a protein structure should be less than $2.25 \mathrm{~A}^{\circ}$ (RMSF). When we looked at the ligand-free protein structure(2WGJ), Crizotinib bounded protein(2WGJ(PDB(P6)) and Crizotinib and Temozolomide bounded protein structure (2WGJ(PDB(P6) $<-P D B(P 1))$ of 2WGJ, we could understand that the amino acid residues between VAL1092 and GLY1102, there is a higher fluctuation occurred in this region and the RMSF value is above $2.25 \mathrm{~A}^{\circ}$. However, in the case of the combination of Crizotinib and Temozolomide bounded protein structure, the value is below $2 A^{\circ}$. In the amino acid residues between SER1152 and HIS1162, there is only minimal fluctuation occurred in this region by the drug Crizotinib bounded on the amino acid residue PRO1158, MET1160 and there is a lower fluctuation occurred in the downward direction when the drug Temozolomide drug bounded on the amino acid residues ASN1167. 
Look on the RMSF graph of 3ZBF (PDB(P6)<-PDB(P4)); there are no higher fluctuations occurred in the amino acid residues when compared to ligand bounded Crizotinib complex(3ZBF(PDB(P6)). We could also identify that the terminal residues of the left corner of free protein have higher fluctuation above $2.25 \mathrm{~A}^{\circ}$. Also, we can see that right corner of the terminal residues of ligand-free protein (3ZBF) and Crizotinib bounded protein structure, there is a higher fluctuation in amino acid residues, and RMSF values in this region also had gone above $2.25 \mathrm{~A}^{\circ}$. But the overall fluctuations of combination drug Crizotinib and Temozolomide bounded protein complex (3ZBF (PDB (P6) <-PDB (P4)) is less than 2.25 $\mathrm{A}^{\circ}$. Also, when we look at the amino acid residues between ILE2024 and LEU2034, there is a downward fluctuation occurred. This is the region where the first drug Crizotinib bounded on the amino acid residues GLU2027, MET2029, and ASP2033. The second drug Temozolomide drug binding site, ARG2083, ASP2102, and GLY1954, we could see fewer fluctuations in this region.

In the case of ligand free protein, Crizotinib bounded protein structure and Crizotinib and Temozolomide bounded protein structure 2XP2 (RC (S1, P8) <-PDB (P2)) of 2XP2, all these three structures, RMSF fluctuation ratio is below $2.25 \mathrm{~A}^{\circ}$, and there is a minor fluctuation occurred in three structures. When comparing the Crizotinib bounded protein complex(2XP2(RC(S1, P8)) and Crizotinib and Temozolomide protein complexes of 2XP2(2XP2(RC(S1, P8)<-PDB(P2)), the drug Crizotinib bounded key amino acid residues GLU1197, MET1199, and Temozolomide region LY1150, there is no more fluctuations occurred in both the structure when compared to the ligand-free protein structure of 2XP2. The overall fluctuation rate of Crizotinib and Temozolomide with 2XP2 protein structure (2XP2 (2XP2 (RC (S1, P8)<-PDB(P2))) was significantly less compared to Crizotinib bounded protein structure.

\section{Structural analysis studies of the best-docked combination drug complexes}

In the combination docking of Crizotinib and Temozolomide with C-MET,C-ROS1 and ALK proteins, we identified 2WGJ(PDB(P6)<-PDB(P1)), 3ZBF(PDB(P6)<$\mathrm{PDB}(\mathrm{P} 4))$ and 2XP2(RC(S1, P8)<-PDB(P2)) are most stable complexes by MD simulation. In the binding site of 2WGJ(PDB(P6)<-PDB(P1)) docked complex, a total of 30 noncovalent bond interactions formed by Crizotinib and Temozolomide drugs. In the first binding site of this complex, 22 noncovalent bond interactions were formed between the drug Crizotinib and the amino acid residues. Which include hydrogen bond, hydrophobic and electrostatic interactions. The hydrogen bond interaction includes 3 conventional hydrogen bonds( ASP1164,PR01158(2 times)) and the 3 carbon-hydrogen bond(ILE1084,ASP1164,MET1160). The electrostatic interaction which includes one attractive charge(ASP1164). And the main hydrophobic interactions were 7 alkyl interaction (ALA1221,ALA1226(2 times),LEU115,LEU1140,VAL1092,LEU1157) and 8 Pi-alkyl interaction(TYR1230(2 times,ILE1084(2 times), ALA1108,MET1211(3 times). The second drug Temozolomide formed a total of seven noncovalent bond interactions at the protein binding site (PDB (P2), which includes two conventional hydrogen bonds (ASN1167 (2times)), one carbon-hydrogen bond interaction (ILE1084). The electrostatic interaction includes one Pi-anion (ASP1164) interaction. The hydrophobic interaction includes one amide-pi stacked interaction formed by the amino acid residue TYR1230, ASP1231 with Temozolomide drug, and one Pi- alkyl interaction formed by ARG1208 and Temozolomide drug. Apart from drugs with amino acid noncovalent bond interactions, we also identified one drug-drug interaction with Crizotinib and Temozolomide at protein binding sites (5394:H17 $-: 11626560$ :F3-Hydrogen bond).

From the combination drug complex 3ZBF(PDB(P6)<-PDB(P4)), a total of 23 drug interactions had formed by Crizotinib and Temozolomide drug on the active site of 3ZBF protein. The main noncovalent bond interactions formed were hydrogen bonds, hydrophobic, and electrostatic interactions. In which Crizotinib drug generated 16 interactions with the amino acid residues of the protein at the binding site. Which included six hydrogen bonds ( 3 convention hydrogen bonds (ASP2033, GLU2027, GLU2027) and three carbon-hydrogen bond interactions (ASP2033, MET2029 (2 times)). The main hydrophobic interaction with amino acid residues and Crizotinib drug were five alkyl interactions(LEU2086, LEU2010, LEU2026, VAL1959, LYS1980) and four Pi-alkyl interactions(LEU1951, ALA1978, LEU2086(2times)). The electrostatic interaction formed with amino acid residue ASP2033 and the Crizotinib drug. The second drug Temozolomide formed seven interactions with the amino acids at the binding site. Which includes three conventional hydrogen bonds (ARG2083, GLY1954, ASP2102), three carbon-hydrogen bond interactions(ARG2083, ASP2079(2times)) and one Pi-alkyl interaction(ARG2083).

In the combination docking complex, 2XP2 (RC(S1, P8)<-PDB(P2), we could identify 26 noncovalent bond interactions, which includes hydrogen bond and hydrophobic interactions. In this, Crizotinib drug formed (2XP2 (RC (S1, P8)) 20 interactions, which includes two conventional hydrogen bond interactions (MET1199, GLU1197), one carbon-hydrogen bond interaction (MET1199). Hydrophobic interactions found on the binding site with Crizotinib were four alkyl interactions (LEU1196, LEU1256, VAL1130, LEU1196) and 4 Pi-Alkyle interactions (LEU1122, ALA1148, LEU1256 (2times)). Apart from this interaction, another type of interaction found at the binding site was Salt Bridge; Attractive Charge hydrogen bond interaction (GLU1210). Apart from this interaction, we could also find out 8 drug -drug interaction at the binding site, which include alkyle( 11626560:C12-5394,11626560:C25-5394), pi-alkyle(11626560:C13:5394, 11626560:C11:5394(2times), 11626560:C25:5394) and Pi-Pi stacked(11626560-5394(2 times)). The second drug Temozolomide drug formed 6 non covalent bond interaction at the binding site of Crizotinib docked complex structure 2XP2 (RC (S1, P8)). Which include one conventional hydrogen bond interaction (LYS1150) and two carbon-hydrogen bond interactions (HIS1124, ASP1270). The hydrophobic interactions included one alkyl interaction (LYS1150) and two Pi-alkyl interactions (ALA1126 (2times)). The details of intermolecular interaction of Crizotinib and Temozolomide on the binding site of C-MET (2WGJ), CROS1 and ALK protein are shown in the Table 2. The 2D and 3D images of drug interactions of Crizotinib and Temozolomide drug with C-MET, C-ROS1, and ALK protein are mentioned in the Figure 3.

\section{Discussion}

Combination drugs are usually used in many diseases, including cancer and AIDS. The main aim of such types of combinations drugs is to reduce toxicity, decrease or delay drug resistance, and improve drug efficacy, thus increasing survival rate. The drug efficacy of these combination drugs is usually determined by the drug dose ratio, and the efficacy of the drugs is interpreted using various terminologies like additive, agonism, synergism, and antagonism ${ }^{\text {[18] }}$. Efficacy of a drug usually occurs due to the result of intermolecular interaction between drug and DNA/RNA/Protein/Enzyme ${ }^{[19]}$. So the intermolecular interaction studies of combination drugs are significant. The intermolecular interaction of a single drug with protein can be identified by docking software ${ }^{[20]}$. But in the

Page 5/21 
case of combination drug treatment, multiple drug interactions will occur on the binding site of the proteins. So finding out such type of multiple drug interaction are very important in structural biology studies. However, identifying multiple drug interactions with protein is very challenging in docking studies, which are not reported so far now. In the current study, we try to find out the intermolecular interaction of the combination drug Crizotinib and Temozolomide with C-MET, C-ROS1, and ALK targets of GBM. To identify the intermolecular interaction these drugs with proteins, we performed a forward and reverse drug docking with C-MET, C-ROS1, and ALK proteins. From this combination drug docking of 2WGJ, $3 Z$ BF, and 2XP2 proteins, a total of 19 combination drug docked complexes of 2WGJ protein, 30 combination drug docked complexes of $3 Z \mathrm{BF}$ protein, and 32 combination drug docked complexes of $2 \mathrm{XP} 2$ protein were selected based on drug properties and CE. From the result, we could identify that in the single drug docked complexes, Temozolomide drug with C-MET, C-

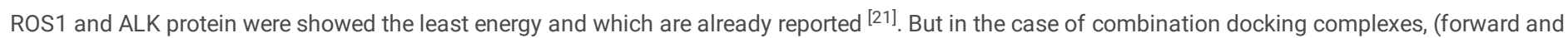
reverse docking of drug with proteins), we could understand the combination drug docked complexes of Crizotinib and Temozolomide with protein 2 WGJ, 3ZBF, and 2XP2 were showed the least energy. The details are mentioned in the Table 1. From this Table, we selected the most stable combination drug complexes of 2WGJ(PDB(P6)<-PDB(P1)), 3ZBF(PDB(P6)<-PDB(P4) and 2XP2(RC(S1, $\mathrm{P} 8)<-P D B(P 2))$ by MD simulation run, which are mentioned in the Table 2. In the Combination drug complex 2WGJ(PDB(P6)<-PDB(P1), the drug pose number six of the Crizotinib drug and pose number one of Temozolomide drugs were interacts with the key amino acid residues PR01158, MET1160 (Crizotinib), ASN1167 on the active site of the 2WGJ protein by the PDB method. The

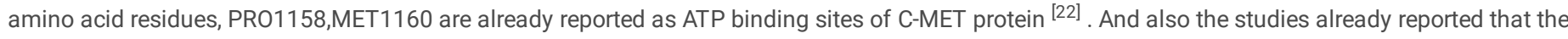
Asparagine amino acid promotes cancer cell proliferation ${ }^{[27]}$. So the binding of Temozolomide drug in ASN1167 amino acid residue will lead to the inhibition of protein activity. So we can say that the binding of combination drug Crizotinib and Temozolomide drug action will strongly inhibit the activity of tyrosine kinase protein 2 WGJ function in GBM cancer.

In docked combination drug complex 3ZBF(PDB(P6)<-PDB(P4), the drug pose number six of Crizotinib and drug pose number four of Temozolomide drug were bound on the protein active site by PDB method. The first drug Crizotinib binded on the amino acid residue GLU2027, MET2029, and ASP2033 and Temozolomide binded on the ARG2083, ASP2102, and GLY1954 residues. Here also both the drug binding on the ATP and methylation site of the protein $[23,28,29,30,31]$. Docking of Crizotinib and Temozolomide drug with 2XP2 protein, we got the least energy complex was 2XP2 (RC (S1, P8)<-PDB(P2)). In this docked complex, pose number eight of Crizotinib binded at first sight of the protein by RC method and pose number two of temozolomide drug binded on the second site of protein by PDB method. In the first active site, Crizotinib drug binded on the amino acid residues GLU1197, MET1199, and Temozolomide binded on the amino acid residue LYS1150 showed a strong hydrogen bond interaction at the binding site. Amino acid residues GLU1197, MET1199 were reported as ATP binding sites of 2XP2 protein and also reported that the binding action of Crizotinib drug on these amino acid residues ${ }^{\text {[22] }}$. The Temozolomide drug action on Lysine amino acid residue was also reported ${ }^{[28,29]}$. Based on the intermolecular interaction of Crizotinib and Temozolomide drug on 2WGJ,3ZBf, and 2XP2 protein, we can say that the combined effect of Crizotinib and Temozolomide binding will give more potent inhibition in these proteins rather than Crizotinib alone action in C-MET, C-ROS1, and ALK protein.

\section{Methods}

The software used for the docking study was Discovery Studio 2018(v18.1.100.18065), Server: DCBDELL-DSSERVER1. The online resources used for the study were Uniprot, PDB, NCBI, PDBsum, and PubChem databases. We downloaded the 3D structure of target proteins 3ZBF(C-ROS1), 2WGJ(C-MET), 2XP2 (ALK) from PDB[32] and the details of X-ray crystallographic structures of these protein complex) and their hydrogen bond interaction with Crizotinib drug are shown in Table4.

Here, all the protein structures have only one chain. Moreover, the specific functional region found at MET and GLU amino acid residues in 2XP2 and 3ZBF protein structures, but in 2WGJ protein, reported at MET and PRO amino acid residues.

The small molecules downloaded from PubChem databases for the docking studies ${ }^{[33]}$ and the 2D images and Chemical properties of both Crizotinib and Temozolomide are shown in Table5.

\section{Docking}

For docking studies, we used the Libdock tool of Biovia Discovery Studio2018 ((Ref: Discovery studio user manual) ${ }^{[34]}$. The reason is that Libdock will generate hundreds of pose conformations for a single molecule, and also it shows good scoring accuracy in drug poses ${ }^{[35,36]}$. The pipeline used for the docking study is shown in Figure4.

Before docking, we prepared the ligand and protein molecules. In protein preparation, the ligand molecule was removed from all the protein structures. Then protein preparation is performed with an automatic preparation tool of BIOVIA Discovery studio(Ref; Discovery studio user manual). Then the drug molecules Crizotinib and Temozolomide were prepared and minimized by ligand preparation and minimization tool of BIOVIA Discovery Studio 2018. This tool minimized the ligand using 2000 steps by smart minimizer algorithm and set RMS gradient at 0.01 . CHARMm force fields were used in both the tools ${ }^{[37]}$. After the preprocessing of ligands and proteins, we identified the protein's active site for docking by the following methods.

PDB Site record: Here active site of the protein was identified by the already reported binding region from the PDB file.

Receptor Cavity (RC): In this method, the protein's binding site is derived from large cavities of the protein structure.

Direct/Site-specific method: Here, the active site is selected based on prior knowledge about key amino acid residues. In C-MET, C-ROS1, and ALK proteins, we selected the amino acid residues were (PRO1158, MET1160), (GLU2027 MET2029) and (GLU1197, MET1199) respectively. 
Motif-based method: Here, we selected the DFG motif of each RTKs protein along with key amino acid residues. Because the DFG motif of RTKs protein has significant role in activating the kinase protein activity [ 38 ]. In C-MET, C-ROS1, and ALK proteins, we selected key amino acid residues and DFG motif were (PR01158, MET1160, and the DFG motif were ASP1222, PHE1223, GLY1224), (GLU2027, MET2029, and the DFG motif were ASP2102, PHE2103, GLY2104) and (GLU1197, MET 1199, and the DFG motifs were ASP1270, PHE1271, GLY1272) respectively.

After the active site identification, we performed two types of docking in each protein's structure by libdock tool.

1. Docking of Crizotinib and Temozolomide drugs with C-MET, C-ROS1, and ALK proteins (forward docking of drugs with proteins).

2. Docking of Temozolomide and Crizotinib drugs with C-MET, C-ROS1, and ALK proteins (reverse docking of drugs of drug with proteins).

In forward and reverse docking of drugs with proteins, we selected the best-docked complex based on drug properties and complex energy (CE). The Crizotinib drug properties are that, which an inhibitor of RTKs proteins. Which mainly bind on the protein's ATP binding region and thus by inhibiting the protein from phosphorylation. Crizotinib action on C-MET, C-ROS1, and ALK have already been reported ${ }^{[22,23]}$. Temozolomide drug is an Alkylating agent. It mainly binds on the methylation site of the protein $[28,29,30,31]$. The main aim of forward and reverse docking of combination drug studies was to understand the inter molecular mechanism of Crizotinib and Temozolomide in C-MET, C-ROS1, and ALK proteins. In docking of Crizotinib and Temozolomide with C-MET, C-ROS1, and ALK proteins, we first docked the Crizotinib drug on C-MET protein by each active site identification method. After the first docking, we selected the top ten Crizotinib bounded docked complexes from each docking method. Then we calculate Binding energy and Complex Energy. In the Discovery studio tool, calculate the Binding and $\mathrm{CE}$ of a docked complex via the following equation..

Energy binding $=$ Energy complex - Energy ligand - Energy receptor.

Complex Energy $=$ Energy binding + Energy ligand + Energy receptor.

From the result obtained from the analysis study, we selected the least energy showed Crizotinib bounded docked complexes from each docking method. Then we performed a second protein preparation for the least energy docked complexes of each of the docking methods of C-MET protein. Furthermore, again we find out the active site for each of the Crizotinib bounded C-MET protein complexes. Then Temozolomide drug docked on the active site of each of the Crizotinib bounded docked complexes of C-MET protein. Then calculate binding energy and CE of the Temozolomide docked complexes. Here the Complex energy of the docked complex is the sum of the total least energy attained by a docked complex after when the drug molecules bind on its protein active site. Here we got the CE is the sum of the least energy of Crizotinib, and Temozolomide bounded protein structure. Then we filter the least energy docked complexes from Crizotinib and Temozolomide drug bounded docked complexes from each docking method based on drug properties.

In the reverse Docking of Temozolomide and Crizotinib with C-MET protein, we repeat the same procedure applied in the docking of Crizotinib and Temozolomide drug with C-MET protein. Finally we performed MD simulation analysis based on the least energy showed combination drug complexes for identifying stability and flexibility of best combination drug complexes ${ }^{[39]}$.

MD simulation Analysis: Before the MD simulation analysis, we changed the force field of each protein structure from CHARMm to CHARMm36 by the tool, applied force field in DS (Ref. user manual of Simulation protocol in Discovery studio Tool). Then we add water molecules, chloride, and sulfur for each protein structure by solvation tool of DS. By the solvation, the protein structure can interact naturally with the solvent ${ }^{[39]}$. Here all the protein structures were solvated by using explicit periodic boundary condition.

Standard Dynamic Cascade Tool: After applying the forcefield and solvation to each protein structure, we performed MD simulation analysis using two tool panels of Discovery studio2018. One is a standard dynamic cascade tool, and another is Trajectory analysis tool. The standard Dynamic cascade tool is used for helping to simulate the biological conditions for protein structures and protein docked complexes. Before running this tool, we need to set the parameter for simulation. The main parameters set for MD simulation in the tool were Minimization, Heating, Equilibration, and Production. In the minimization part, there are two minimization parts. In the initial part, we set the steepest descent algorithm at 1000 steps, and in the second part, we used the adopted basis NR algorithm at 2000 steps. During heating, the whole system's initial temperature was set from 50 to $300 \mathrm{~K}$ in 4 ps (picosecond) and the simulation time was not controlled, and velocity frequency was set at 50 . Here the result was saved at $2 \mathrm{ps}$. In the equilibration of the system setup, the temperature was adjusted to $300 \mathrm{~K}$, and here also adjusted velocity frequency was set to 50 , and the simulation time was set to 20 ps. In the production, time was set to 200 ps for a run in $300 \mathrm{~K}$ with typed NPT. In the standard Dynamic Cascade tool, all the remaining parameters were set as by default value. In the standard Dynamic cascade tool, the total time allocated for heating, equilibration, and production was $224 \mathrm{ps}$. Here in all the combination drug docked complexes, we performed the MD simulation run based on picosecond. The main reason for performing picosecond is that it is a study of combination drug docked complex. So if we run the combination drug complexes in nanoseconds, it will require more memory and run time. For considering these things, in the present study, we set an equilibration time as 224 picoseconds in all the protein structures. In MD simulation, there is 3 type of MD simulation run we performed on each protein structure which include free protein structure, single drug bounde complex, and combination drug bounded complexes of C-MET,C-ROS1 and ALK. After the MD simulation run, we performed trajectory analysis study for each complex to understand the conformational stability and flexibility of the single and combination docked complex by using trajectory analysis tool of discovery studio2018 (Ref., the user manual of MD simulation tutorial of Discovery studio2018). In trajectory analysis, the nosolvent file of each docked complex structure was used as a reference molecule. In the parameter boxes RMSD, RMSF, and properties were selected, and also set atom group, atom group to fit parameter for each protein structure was set as Backbone. The remaining parameters were set as by default value.

\section{Abbreviations}


WHO: World Health Organization, GBM: Glioblastoma multiforme, NSCLC: non-small-cell lung carcinoma, RTKs: Receptor tyrosine kinases, CE: Complex Energy, RC: Receptor Cavity, DS: Discovery Studio.

\section{Declarations}

\section{Acknowledgments}

We would like to thanks the University of Kerala, the State Interuniversity Center of Excellence in Bioinformatics (SIUCE, Govt. of Kerala), Dept. of Biotechnology (DBT-BIF project), Govt. of India. for providing all the facilities for doing this work.

\section{Author's contributions}

SY performed all the research activities, VC and ASN monitored the research work and SY, SK and VC participated in preparing and drafting the manuscript. All authors read and approved the final manuscript.

\section{Ethics approval and consent to participate}

Not Applicable.

\section{Consent for publication}

Not applicable

\section{Availability of data and material}

All necessary data generated or analyzed during this study are included in this article. Any additional data could be available from the corresponding author upon request.

\section{Competing interests}

The authors declare that they have no competing interests

\section{Funding}

This research did not receive any specific grant from funding agencies in the public, commercial, or not-for-profit sectors.

\section{References}

1. Hanif, F., Muzaffar, K., Perveen, K., Malhi, S. M., \& Simjee, S. (2017). Glioblastoma Multiforme: A Review of its Epidemiology and Pathogenesis through Clinical Presentation and Treatment. Asian Pacific journal of cancer prevention: APJCP, 18(1), 3-9. https://doi.org/10.22034/APJCP.2017.18.1.3.

2. Wrensch, M., Minn, Y., Chew, T., Bondy, M., \& Berger, M. S. (2002). Epidemiology of primary brain tumors: current concepts and review of the literature. Neuro-oncology, 4(4), 278-299. https://doi.org/10.1093/neuonc/4.4.278

3. Chakrabarti, I., Cockburn, M., Cozen, W., Wang, Y. P., \& Preston-Martin, S. (2005). A population-based description of glioblastoma multiforme in Los Angeles County, 1974-1999. Cancer, 104(12), 2798-2806. https://doi.org/10.1002/cncr.21539

4. Stupp, R., Mason, W. P., Van Den Bent, M. J., Weller, M., Fisher, B., Taphoorn, M. J., ... Curschmann, J. (2005). Radiotherapy plus concomitant and adjuvant temozolomide for glioblastoma. New England journal of medicine, 352(10), 987-996.

5. Davis M. E. (2016). Glioblastoma: Overview of Disease and Treatment. Clinical journal of oncology nursing, 20(5 Suppl), S2-S8. https://doi.org/10.1188/16.CJON.S1.2-8

6. Das, A., Cheng, R. R., Hilbert, M. L., Dixon-Moh, Y. N., Decandio, M., Vandergrift, W. A., 3rd, Banik, N. L., Lindhorst, S. M., Cachia, D., Varma, A. K., Patel, S. J., \& Giglio, P. (2015). Synergistic Effects of Crizotinib and Temozolomide in Experimental FIG-ROS1 Fusion-Positive Glioblastoma. Cancer growth and metastasis, 8, 51-60. https://doi.org/10.4137/CGM.S32801.

7. Awad MM, Katayama R, McTigue M, et al. Acquired resistance to crizotinib from a mutation in CD74-ROS1. N Engl J Med. 2013;368(25):2395-2401.

8. Bebb, D. G., Agulnik, J., Albadine, R., Banerji, S., Bigras, G., Butts, C., Couture, C., Cutz, J. C., Desmeules, P., lonescu, D. N., Leighl, N. B., Melosky, B., Morzycki, W., Rashid-Kolvear, F., Lab, C., Sekhon, H. S., Smith, A. C., Stockley, T. L., Torlakovic, E., Xu, Z., ... Tsao, M. S. (2019). Crizotinib inhibition of ROS1-positive tumours in advanced non-small-cell lung cancer: a Canadian perspective. Current oncology (Toronto, Ont.), 26(4), e551-e557.

https://doi.org/10.3747/co.26.5137.

9. Camidge DR, Ou S-HI, Shapiro G, et al. Efficacy and safety of crizotinib in patients with advanced C-MET-amplified non-small cell lung cancer (NSCLC). J Clin Oncol 2014;32:abstr 8001 
10. Sahu, A., Prabhash, K., Noronha, V., Joshi, A., \& Desai, S. (2013). Crizotinib: A comprehensive review. South Asian journal of cancer, $2(2), 91-97$. https://doi.org/10.4103/2278-330X.110506.

11. Le Rhun, E., Chamberlain, M. C., Zairi, F., Delmaire, C., Idbaih, A., Renaud, F., Maurage, C. A., \& Grégoire, V. (2015). Patterns of response to crizotinib in recurrent glioblastoma according to ALK and MET molecular profile in two patients. CNS oncology, 4(6), 381-386. https://doi.org/10.2217/cns.15.30.

12. Nehoff, H., Parayath, N. N., McConnell, M. J., Taurin, S., \& Greish, K. (2015). A combination of tyrosine kinase inhibitors, crizotinib and dasatinib for the treatment of glioblastoma multiforme. Oncotarget, 6(35), 37948-37964. https://doi.org/10.18632/oncotarget.5698.

13. Lev, A., Deihimi, S., Shagisultanova, E., Xiu, J., Lulla, A. R., Dicker, D. T., \& El-Deiry, W. S. (2017). Preclinical rationale for combination of crizotinib with mitomycin C for the treatment of advanced colorectal cancer. Cancer biology \& therapy, 18(9), 694-704. https://doi.org/10.1080/15384047.2017.1364323.

14. Li, Y., Zhang, R., Zhou, Y., Song, J., Luo, W., Tian, P., \& Li, W. (2019). Combined Use of Crizotinib and Gefitinib in Advanced Lung Adenocarcinoma With Leptomeningeal Metastases Harboring MET Amplification After the Development of Gefitinib Resistance: A Case Report and Literature Review. Clinical lung cancer, 20(3), e251-e255. https://doi.org/10.1016/j.cllc.2018.12.004.

15. Tallarida R. J. (2011). Quantitative methods for assessing drug synergism. Genes \& cancer, 2(11), 1003-1008. https://doi.org/10.1177/1947601912440575.

16. Chou TC Theoretical basis, experimental design, and computerized simulation of synergism and antagonism in drug combination studies. Pharmacol Rev 2006;68:621-81, (Free web link: http://pharmrev.aspetjournals.org/cgi/reprint/58/3/621).

17. Adamus-Grabicka, A. A., Markowicz-Piasecka, M., Ponczek, M. B., Kusz, J., Małecka, M., Krajewska, U., \& Budzisz, E. (2018). Interaction of Arylidenechromanone/Flavanone Derivatives with Biological Macromolecules Studied as Human Serum Albumin Binding, Cytotoxic Effect, Biocompatibility Towards Red Blood Cells. Molecules, 23(12), 3172.

18. Chou TC, Talalay P. Quantitative analysis of dose-effect relationships: the combined effects of multiple drugs or enzyme inhibitors. Adv Enzyme Regul 1984;22:27-55.

19. https://sites.duke.edu/thepepproject/module-5-why-do-plants-make-drugs-for-humans/content-background-how-does-a-drug-interact-with-its-target-its-allin-the-chemistry/

20. Meng XY, Zhang HX, Mezei M, Cui M. Molecular docking: a powerful approach for structure-based drug discovery. Current Computer Aided Drug Des. 2011 Jun;7(2):146-57. doi: 10.2174/157340911795677602. PMID: 21534921; PMCID: PMC3151162.

21. Younus, S., Vinod Chandra, S. S., \& Nair, A. S. S. (2021). Docking and dynamic simulation study of Crizotinib and Temozolomide drug with Glioblastoma and NSCLC target to identify better efficacy of the drug. Future Journal of Pharmaceutical Sciences, 7(1), 1-17.

22. Cui, J. J., Tran-Dubé, M., Shen, H., Nambu, M., Kung, P. P., Pairish, M., ... McTigue, M. (2011). Structure based drug design of Crizotinib (PF-02341066), a potent and selective dual inhibitor of mesenchymal-epithelial transition factor (C-MET) kinase and anaplastic lymphoma kinase (ALK). Journal of medicinal chemistry, 54(18), 6342-6363.

23. Awad, M. M., Katayama, R., McTigue, M., Liu, W., Deng, Y. L., Brooun, A., \& Wilner, K. D. (2013). Acquired resistance to Crizotinib from a mutation in CD74ROS1. New England Journal of Medicine, 368(25), 2395-2401.

24. Hyndman, R. J., \& Koehler, A. B. (2006). Another look at measures of forecast accuracy. International journal of forecasting, 22(4), 679-688.

25. Wang, W., Li, X., Wang, Q., Zhu, X., Zhang, Q., \& Du, L. (2018). The acidic pH-induced structural changes in apo-CP43 by spectral methodologies and molecular dynamics simulations. Journal of Molecular Structure, 1152, 177-188.

26. Xi, L., Wang, Y., He, Q., Zhang, Q., \& Du, L. (2016). Interaction between Pin1 and its natural product inhibitor epigallocatechin-3-gallate by spectroscopy and molecular dynamics simulations. Spectrochimica Acta Part A: Molecular and Biomolecular Spectroscopy, 169, 134-143.

27. Krall, A. S., Xu, S., Graeber, T. G., Braas, D., \& Christofk, H. R. (2016). Asparagine promotes cancer cell proliferation through use as an amino acid exchange factor. Nature communications, $7(1), 1-13$.

28. Wang, T., Pickard, A. J., \& Gallo, J. M. (2016). Histone methylation by Temozolomide; a classic DNA methylating anti-cancer drug. Anti-cancer research, 36(7), 3289-3299.

29. Pang, C.N.I., Gasteiger, E. \& Wilkins, M.R. Identification of Arginine- and lysine-methylation in the proteome of Saccharomyces cerevisiae and its functional implications. BMC Genomics 11, 92 (2010). https://doi.org/10.1186/1471-2164-11-92.

30. Carlson, S. M., \& Gozani, O. (2016). Nonhistone Lysine Methylation in the Regulation of Cancer Pathways. Cold Spring Harbor perspectives in medicine, 6(11), a026435. https://doi.org/10.1101/cshperspect.a026435.

31. Butt, A. M., Feng, D., Idrees, M., Tong, Y., \& Lu, J. (2012). Computational identification and modeling of crosstalk between phosphorylation, O- $\beta$ glycosylation and methylation of FoxO3 and implications for cancer therapeutics. International journal of molecular sciences, 13(3), 2918-2938.

32. H.M. Berman, J. Westbrook, Z. Feng, G. Gilliland, T.N. Bhat, H. Weissig, I.N. Shindyalov, P.E. Bourne.(2000) The Protein Data Bank Nucleic Acids Research, 28: 235-242.

33. Kim, S., Chen, J., Cheng, T., Gindulyte, A., He, J., He, S., ... Zaslavsky, L. (2019). PubChem 2019 update: improved access to chemical data. Nucleic acids research, 47(D1), D1102-D1109.

34. Dassault Systèmes BIOVIA. Discovery Studio Modeling Environment, Release 2017. Dassault Systèmes; San Diego, CA, USA: 2017. https://www.3dsbiovia.com/products/collaborative-science/biovia-discovery-studio/.

35. Rao, S. N., Head, M. S., Kulkarni, A., \& LaLonde, J. M. (2007). Validation studies of the site-directed docking program LibDock. Journal of chemical information and modeling, 47(6), 2159-2171.

Page $9 / 21$ 
36. Diller, D. J., \& Merz Jr, K. M. (2001). High throughput docking for library design and library prioritization. Proteins: Structure, Function, and Bioinformatics, 43(2), 113-124.

37. Brooks, B. R., Brooks III, C. L., Mackerell Jr, A. D., Nilsson, L., Petrella, R. J., Roux, B., ... Karplus, M. (2009). CHARMM: the biomolecular simulation program. Journal of computational chemistry, 30(10), 1545-1614.

38. Peng, Y. H., Shiao, H. Y., Tu, C. H., Liu, P. M., Hsu, J. T. A., Amancha, P. K., ... Lin, W. H. (2013). Protein kinase inhibitor design by targeting the Asp-Phe-Gly (DFG) motif: the role of the DFG motif in the design of epidermal growth factor receptor inhibitors. Journal of medicinal chemistry, 56(10), 3889-3903.

39. Lin, C. H., Chang, T. T., Sun, M. F., Chen, H. Y., Tsai, F. J., Chang, K. L., ... Chen, C. Y. C. (2011). Potent inhibitor design against H1N1 swine influenza: structure-based and molecular dynamics analysis for M2 inhibitors from traditional Chinese medicine database. Journal of Biomolecular Structure and Dynamics, 28(4), 471-482.

\section{Tables}

\section{Table 1}

Details of combination drug position, docking method, docking score, binding energy, complex energy and hydrogen bond interaction showed amino acid residues at the binding site of protein with the both the drug molecules 


\begin{tabular}{|c|c|c|c|c|c|c|c|}
\hline \multirow[t]{4}{*}{ SI:No } & \multirow{4}{*}{$\begin{array}{l}\text { Protein } \\
\text { Name }\end{array}$} & \multirow{2}{*}{\multicolumn{2}{|c|}{$\begin{array}{l}\text { Name of the drug docked with } \\
\text { Position number \&Type of docking }\end{array}$}} & \multirow[t]{4}{*}{ Docking score } & \multirow[t]{4}{*}{ Binding energy } & \multirow[t]{4}{*}{ Complex Energy } & \multirow{3}{*}{$\begin{array}{l}\text { Interacting } \\
\text { Amino acid on the } \\
\text { Druggable }\end{array}$} \\
\hline & & & & & & & \\
\hline & & First position & Temozolomide & & & & \\
\hline & & Crizotinib & Second Position & & & & Binding site \\
\hline \multicolumn{8}{|c|}{ Docking of Crizotinib and Temozolomide with 2WGJ (C-MET) proein } \\
\hline \multirow[t]{5}{*}{ I } & 2WGJ & PDB(P6) & & 139.105 & -44.1433 & -11179.9569 & PR01158, \\
\hline & & & & & & & MET1160 \\
\hline & & & $\mathrm{PDB}(\mathrm{P} 1)$ & 76.6468 & -22.3612 & -11252.7717 & ASN1167 \\
\hline & & & $\mathrm{RC}(\mathrm{S} 3, \mathrm{P} 4)$ & 55.9085 & -3.5582 & -11257.2432 & ARG1166, \\
\hline & & & & & & & ARG1170 \\
\hline \multirow[t]{5}{*}{ II } & 2WGJ & $\mathrm{RC}(\mathrm{S} 2, \mathrm{P} 4)$ & & 137.169 & -15.3749 & -11155.5712 & PR01158 \\
\hline & & & & & & & MET1160 \\
\hline & & & & & & & ASP1164 \\
\hline & & & $\mathrm{RC}(\mathrm{S} 3, \mathrm{P} 7)$ & 55.1107 & -31.9594 & -11255.6352 & ARG1166 \\
\hline & & & & & & & ARG1170 \\
\hline \multirow[t]{4}{*}{ III } & 2WGJ & DIRECT(P2) & & 106.855 & 114.7614 & -11028.5560 & ASP1164 \\
\hline & & & & & & & PR01158 \\
\hline & & & $\mathrm{RC}(\mathrm{S} 1, \mathrm{P} 5)$ & 66.021 & -17.4212 & -11256.9253 & ARG1227, \\
\hline & & & & & & & GLU1127 \\
\hline \multicolumn{8}{|c|}{ Docking of Temozolomide with Crizotinib in 2WGJ(C-ROS1) protein } \\
\hline \multirow[t]{5}{*}{ I } & 2WGJ & $\mathrm{PDB}(\mathrm{P} 4)$ & & 74.4989 & -16.3492 & -11289.7872 & MET1160, \\
\hline & & & & & & & PR01158 \\
\hline & & & $\mathrm{RC}(\mathrm{S} 1, \mathrm{P} 5)$ & 120.453 & 222.3001 & -10942.6807 & GLU1127, \\
\hline & & & & & & & ARG1203, \\
\hline & & & & & & & LYS1244 \\
\hline \multirow[t]{8}{*}{ II } & 2WGJ & $\mathrm{RC}(\mathrm{S} 1, \mathrm{P} 4)$ & & 67.5009 & -25.2079 & -11302.4869 & ARG1227 \\
\hline & & & PDB(P3) & 139.545 & -44.8256 & -11201.0974 & PR01158 \\
\hline & & & & & & & MET1160 \\
\hline & & & & & & & ASP1164 \\
\hline & & & $\mathrm{RC}$ & 130.605 & -47.1786 & -11208.0049 & PR01158 \\
\hline & & & (S1,P9) & & & & ASP1164 \\
\hline & & & DIRECT & 102.995 & 46.5792 & -11101.4491 & HIS1174, \\
\hline & & & (P5) & & & & HIS1162 \\
\hline \multirow[t]{5}{*}{ III } & 2WGJ & DIRECT(P4) & & 68.0813 & -27.8584 & -11305.0830 & MET1160 \\
\hline & & & & & & & PR01158 \\
\hline & & & PDB(P2) & 96.639 & 324.7148 & -10338.8302 & HIS1174, \\
\hline & & & & & & & HIS1162 \\
\hline & & & DIRECT(P3) & 75.5657 & -7.2221 & -11174.3462 & SER1141 \\
\hline \multirow[t]{5}{*}{ IV } & 2WGJ & MOTIF(P1) & & 74.7354 & -32.2530 & -11309.5066 & ARG1208 \\
\hline & & & & & & & ASP1222 \\
\hline & & & $\mathrm{PDB}(\mathrm{P} 7)$ & 85.338 & 72.5417 & -11075.2379 & ASP1164, \\
\hline & & & & & & & PR01158 \\
\hline & & & $\mathrm{RC}$ & 120.453 & 222.3001 & -10927.2889 & GLU1127, \\
\hline
\end{tabular}

Page $11 / 21$ 
LYS1244

\section{Docking of Crizotinib and Temozolomide with 3ZBF(C-ROS1) protein}

I. $3 Z B F-P D B(P 6)$

113.349

$-106.9428$

$-11509.9762$

GLU2027

MET2029

ASP2033

PDB(P4)

61.7993

$-49.6139$

$-11629.5730$

ARG2083

ASP2102

GLY1954

$\mathrm{RC}(\mathrm{S} 1, \mathrm{P} 2)$

61.06

$-18.5902$

$-11599.3423$

ARG2083

ARG2084,

ARG2116

II. $3 Z B F \quad R C(S 4, P 4)$

$\operatorname{MOTIF(P)2~}$

67.5562

$-29.2580$

$-11607.5555$

HIS2006

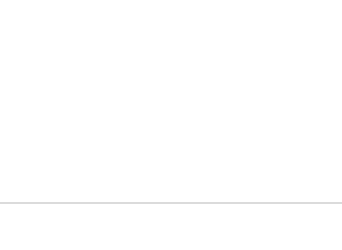

III. 3ZBF DIRECT(P3)

PDB(P4)

92.346

$-62.0108$

$-11400.4896$

GLU2027

MET2029

ARG2083

GLY1954

ASP2102

$\mathrm{RC}(\mathrm{S} 1, \mathrm{P} 10)$

MOTIF(P1)

61.7993

$-49.6139$

$-11629.5730$

ASP2102

\begin{tabular}{llll} 
& 98.9302 & -20.1590 & -11473.5427 \\
\hline PDB(P3) & 60.372 & -42.3390 & -11621.3128
\end{tabular}

(1)

IV. 3ZBF MOTIF(P1)

\begin{tabular}{lllll} 
& & & & GLY1954, \\
& & & & ASP2102 \\
\hline RC(S6,P7) & 73.5836 & -28.9263 & -11612.0884 & ARG2184 \\
\hline MOTIF(P1) & 70.9263 & -33.3147 & -11616.3849 & HIS2006 \\
& 114.545 & -112.0438 & -11514.2552 & GLU2027
\end{tabular}

\begin{tabular}{|c|c|c|}
\hline \multicolumn{3}{|c|}{ Docking of Temozolomide and Criz } \\
\hline I. & 3ZBF & PDB(P4) \\
\hline II & $3 Z B F$ & $\mathrm{RC}(\mathrm{S} 4, \mathrm{P} 4)$ \\
\hline
\end{tabular}

\begin{tabular}{lllll} 
& & & MET2029 \\
\hline PDB(P8) & 61.366 & -48.3916 & -11640.1262 & ASP2033 \\
\hline RC(S10,P1) & 77.6734 & -9.5586 & -11602.9634 & HIS2006, \\
& & & & MET2001 \\
\hline MOTIF(P1) & 71.168 & -31.2576 & -11628.5371 & HIS2006
\end{tabular}




\begin{tabular}{|c|c|c|c|c|c|c|c|}
\hline & & & \multirow[t]{2}{*}{ DIRECT(P4) } & \multirow[t]{2}{*}{115.213} & \multirow[t]{2}{*}{-3.1848} & \multirow[t]{2}{*}{-11536.9461} & GLU1961, \\
\hline & & & & & & & LEU1951 \\
\hline \multirow[t]{5}{*}{ III } & \multirow[t]{5}{*}{ 3ZBF } & \multirow[t]{5}{*}{ DIRECT(P5) } & & \multirow[t]{2}{*}{56.4637} & \multirow[t]{2}{*}{-12.0296} & \multirow[t]{2}{*}{-11627.0789} & GLU2027, \\
\hline & & & & & & & MET2029 \\
\hline & & & \multirow[t]{3}{*}{ MOTIF(P5) } & \multirow[t]{3}{*}{99.653} & \multirow[t]{3}{*}{29.2318} & \multirow[t]{3}{*}{-11419.0213} & ASP2102, \\
\hline & & & & & & & ALA1955, \\
\hline & & & & & & & ASN2084 \\
\hline \multirow[t]{7}{*}{ IV } & \multirow[t]{7}{*}{$3 Z B F$} & \multirow[t]{7}{*}{ MOTIF(P1) } & & 71.1408 & -29.3576 & -11648.4805 & HIS2006 \\
\hline & & & \multirow[t]{2}{*}{ PDB(P3) } & \multirow[t]{2}{*}{114.039} & -88.7423 & -11494.9503 & GLU2027, \\
\hline & & & & & & & ASP2033 \\
\hline & & & $\mathrm{RC}(\mathrm{S} 4, \mathrm{P} 2)$ & 90.7746 & -8.7221 & -11508.6183 & GLU2027, \\
\hline & & & & & & & MET2029 \\
\hline & & & MOTIF(P7) & 109.688 & -61.2600 & -11520.8136 & GLU2027, \\
\hline & & & & & & & MET2029 \\
\hline Dor & of Criz & nib and Temo & mide with $2 x$ & protein & & & \\
\hline I & $2 \mathrm{XP} 2$ & PDB(P10) & & 113.349 & -106.9428 & -11509.9762 & GLU2027 \\
\hline & & & & & & & MET2029 \\
\hline & & & & & & & ASP2033 \\
\hline & & & PDB(P8) & 64.8012 & -31.3674 & -11774.8799 & LYS1150 \\
\hline & & & & & & & ,ASP1270 \\
\hline & & & $\mathrm{RC}(\mathrm{S} 2, \mathrm{P} 11)$ & 44.583 & -22.7267 & -11766.2218 & ARG1253, \\
\hline & & & & & & & ASN1254, \\
\hline & & & & & & & MET1273 \\
\hline & & & MOTIF(P1) & 50.9253 & -34.9974 & -11776.4960 & LYS1150 \\
\hline II & $2 \mathrm{XP} 2$ & $\mathrm{RC}(\mathrm{S} 1, \mathrm{P} 8)$ & & 108.615 & -189.7012 & -11666.7948 & \\
\hline & & & & & & & MET1199 \\
\hline & & & PDB(P2) & 56.5496 & -37.6981 & -11809.0509 & LYS1150 \\
\hline & & & $\mathrm{RC}(\mathrm{S} 1, \mathrm{P} 6)$ & 41.7402 & -22.1709 & -11793.1981 & LYS1150, \\
\hline & & & & & & & ARG1275 \\
\hline & & & MOTIF(P2) & 51.7183 & -30.2246 & -11800.8150 & LYS1150 \\
\hline III & $2 X P 2$ & DIRECT(P1) & & 118.508 & -193.8604 & -11648.2048 & SER1206,ASP1203,GLU1197,MET1199 \\
\hline & & & PDB(P6) & 65.5961 & -58.1317 & -11801.7198 & ARG1253 \\
\hline & & & $\mathrm{RC}(\mathrm{S} 1, \mathrm{P} 6)$ & 43.8847 & -19.6634 & -11767.1323 & ARG1253 \\
\hline & & & & & & & ,ASN1254, \\
\hline & & & & & & & MET1273 \\
\hline & & & & & & & ,ASP1276 \\
\hline & & & MOTIF(P2) & 60.3589 & -22.0080 & -11765.7266 & LYS1150, \\
\hline & & & & & & & GLY1128, \\
\hline & & & & & & & HIS1124 \\
\hline IV & $2 \times P 2$ & MOTIF(P9) & & 107.35 & -176.1679 & -11656.9972 & GLU1197 \\
\hline & & & & & & & MET1199 \\
\hline & & & & & & & ASP1203 \\
\hline & & & $\mathrm{PDB}(\mathrm{P} 4)$ & 65.0735 & -45.8136 & -11793.3255 & LYS1150, \\
\hline & & & & & & & ASP1270 \\
\hline
\end{tabular}




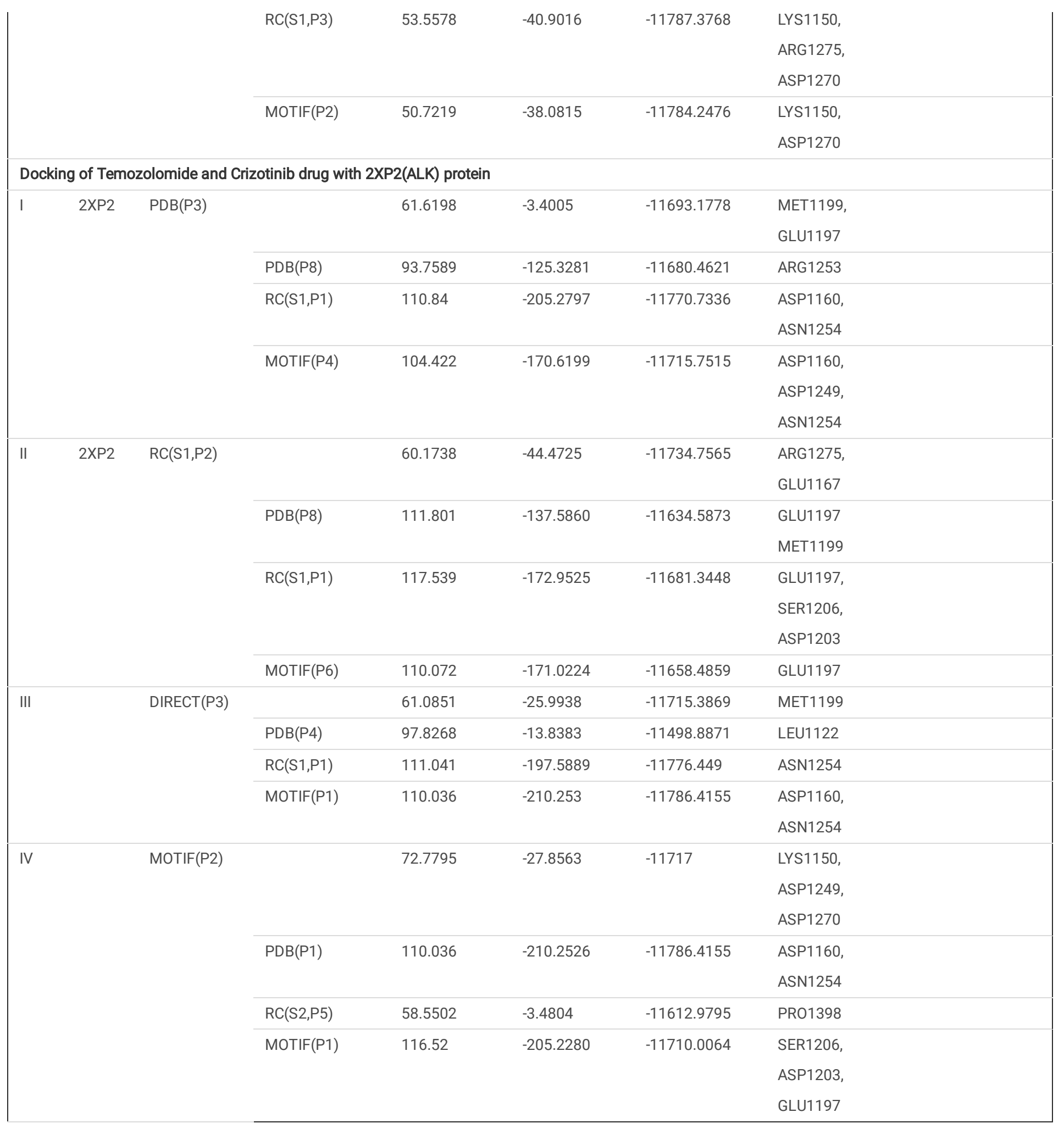

Table 2

Details of best-docked complexes of single and multiple drug binded on the protein C-MET, C-ROS1 and ALK proteins with docking score, binding energy, least complex energy and main hydrogen bond interaction showed amino acid residues on the binding sites selected via MD simulation. 


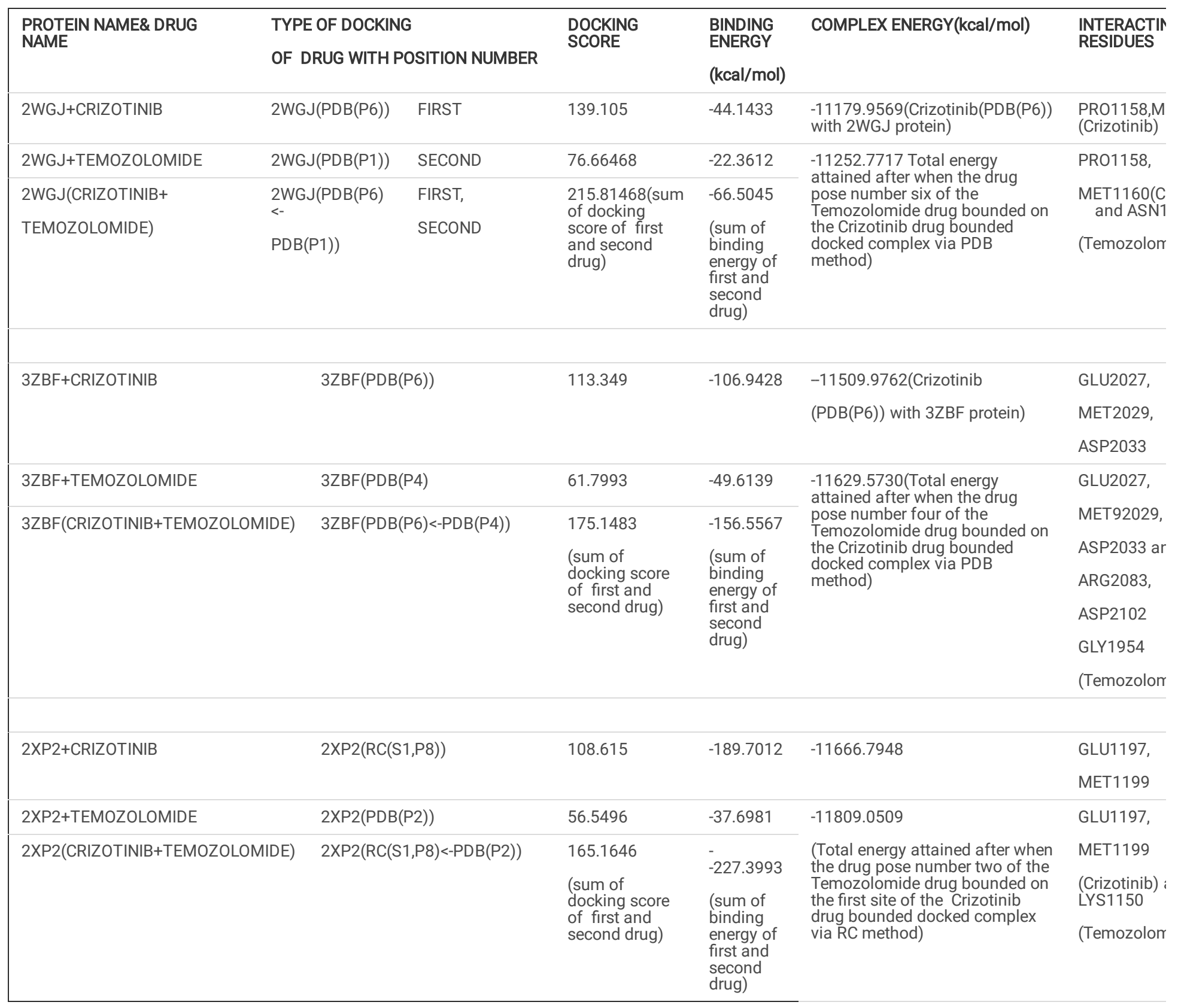

\section{Table 3}

Structural analysis details of best docked complexes of combination drug Crizotinib and Temozolomide bounded protein complexes of C-MET,C-ROS1 and ALK proteins 


\begin{tabular}{|c|c|c|c|c|c|}
\hline $\begin{array}{l}\text { Protein } \\
\text { Name\& Drug Name }\end{array}$ & $\begin{array}{l}\text { Interaction details of docked drug } \\
\text { with drugID, } \\
\text { Docked site details } \\
\text { (First site Crizotinib and second } \\
\text { site Temozolomide) }\end{array}$ & $\begin{array}{l}\text { The interaction details } \\
\text { at the } \\
\text { Binding sites }\end{array}$ & Distance & $\begin{array}{l}\text { Type of } \\
\text { interaction }\end{array}$ & Category \\
\hline \multirow[t]{5}{*}{$\begin{array}{l}\text { 2WGJ(PDB(P6)<- } \\
\text { PDB(P1)) } \\
\text { (Crzotinib(P6)- } \\
\text { Temozolomide(P1) }\end{array}$} & Crizotinib(11626560)-PDB(P6) & $\begin{array}{l}\text { :11626560:H31 - } \\
\text { A:ASP1164:OD1 } \\
: 11626560: H 33 \text { - } \\
\text { A:PR01158:O } \\
: 11626560: H 34 \text { - } \\
\text { A:PR01158:O }\end{array}$ & $\begin{array}{l}2.77861 \\
1.86868 \\
2.2336\end{array}$ & $\begin{array}{l}\text { Conventional } \\
\text { Hydrogen Bond }\end{array}$ & Hydrogen Bond \\
\hline & & $\begin{array}{l}\text { :11626560:H36 - } \\
\text { A:ILE1084:O } \\
\text { :11626560:H44 - } \\
\text { A:ASP1164:OD1 } \\
\text { :11626560:H46 - } \\
\text { A:MET1160:O }\end{array}$ & $\begin{array}{l}2.0732 \\
2.14764 \\
2.50719\end{array}$ & $\begin{array}{l}\text { Carbon } \\
\text { Hydrogen Bond }\end{array}$ & Hydrogen Bond \\
\hline & & :5394:H17 - :11626560:F3 & 2.40487 & $\begin{array}{l}\text { Drug-drug } \\
\text { Interaction(C-H } \\
\text { bond ) }\end{array}$ & Hydrogen Bond \\
\hline & & $\begin{array}{l}\text { :11626560:N6 - } \\
\text { A:ASP1164:OD2 }\end{array}$ & 5.18385 & $\begin{array}{l}\text { Attractive } \\
\text { Charge }\end{array}$ & Electrostatic \\
\hline & & A:TYR1230 - :11626560 & 4.24196 & Pi-Pi Stacked & Hydrophobic \\
\hline \multirow[t]{5}{*}{1} & & $\begin{array}{l}\text { A:ALA1221 - } \\
: 11626560: \mathrm{Cl} 2 \\
\text { A:ALA1226 - } \\
: 11626560: \mathrm{Cl} 2 \\
\text { A:ALA1226 - } \\
: 11626560: \mathrm{C} 25 \\
: 11626560: \mathrm{Cl} 2 \text { - } \\
\text { A:LEU1140 } \\
: 11626560: \mathrm{Cl} 2- \\
\text { A:LEU1157 } \\
: 11626560: \mathrm{C} 25- \\
\text { A:VAL1092 } \\
: 11626560: \mathrm{C} 25- \\
\text { A:LEU1157 }\end{array}$ & $\begin{array}{l}4.97198 \\
5.29497 \\
4.20848 \\
5.18592\end{array}$ & Alkyl & Hydrophobic \\
\hline & & $\begin{array}{l}\text { A:TYR1230 - } \\
: 11626560: C l 1 \\
\text { A:TYR1230 - } \\
: 11626560: C 25 \\
: 11626560 \text { - A:ILE1084 } \\
: 11626560 \text { - A:ALA1108 } \\
: 11626560 \text { - A:MET1160 } \\
: 11626560 \text { - A:MET1211 } \\
: 11626560 \text { - A:MET1211 } \\
: 11626560 \text { - A:ALA1221 }\end{array}$ & $\begin{array}{l}4.4462 \\
4.5456 \\
4.18544 \\
3.50683 \\
4.94339 \\
4.6591 \\
4.64448 \\
4.86609\end{array}$ & Pi-Alkyl & Hydrophobic \\
\hline & \multirow[t]{3}{*}{ Temozolomide(5394)-PDB(P1) } & $\begin{array}{l}\text { A:ASN1167:HD21 - } \\
: 5394: 02 \\
\text { A:ASN1167:HD21 - } \\
: 5394: N 6\end{array}$ & $\begin{array}{l}2.49038 \\
2.01845\end{array}$ & $\begin{array}{l}\text { Conventional } \\
\text { Hydrogen Bond }\end{array}$ & Hydrogen Bond \\
\hline & & :5394:H20 - A:ILE1084:0 & $\begin{array}{l}2.40487 \\
2.44445\end{array}$ & $\begin{array}{l}\text { Carbon } \\
\text { Hydrogen Bond }\end{array}$ & Hydrogen Bond \\
\hline & & $\begin{array}{l}\text { A:ASP1164:OD2 - :5394 } \\
\text { A:TYR1230:C,O;ASP1231:N } \\
-: 5394\end{array}$ & $\begin{array}{l}4.44306 \\
4.27058\end{array}$ & $\begin{array}{l}\text { Pi-Anion } \\
\text { Amide-Pi } \\
\text { Stacked }\end{array}$ & $\begin{array}{l}\text { Electrostatic } \\
\text { Hydrophobic }\end{array}$ \\
\hline
\end{tabular}




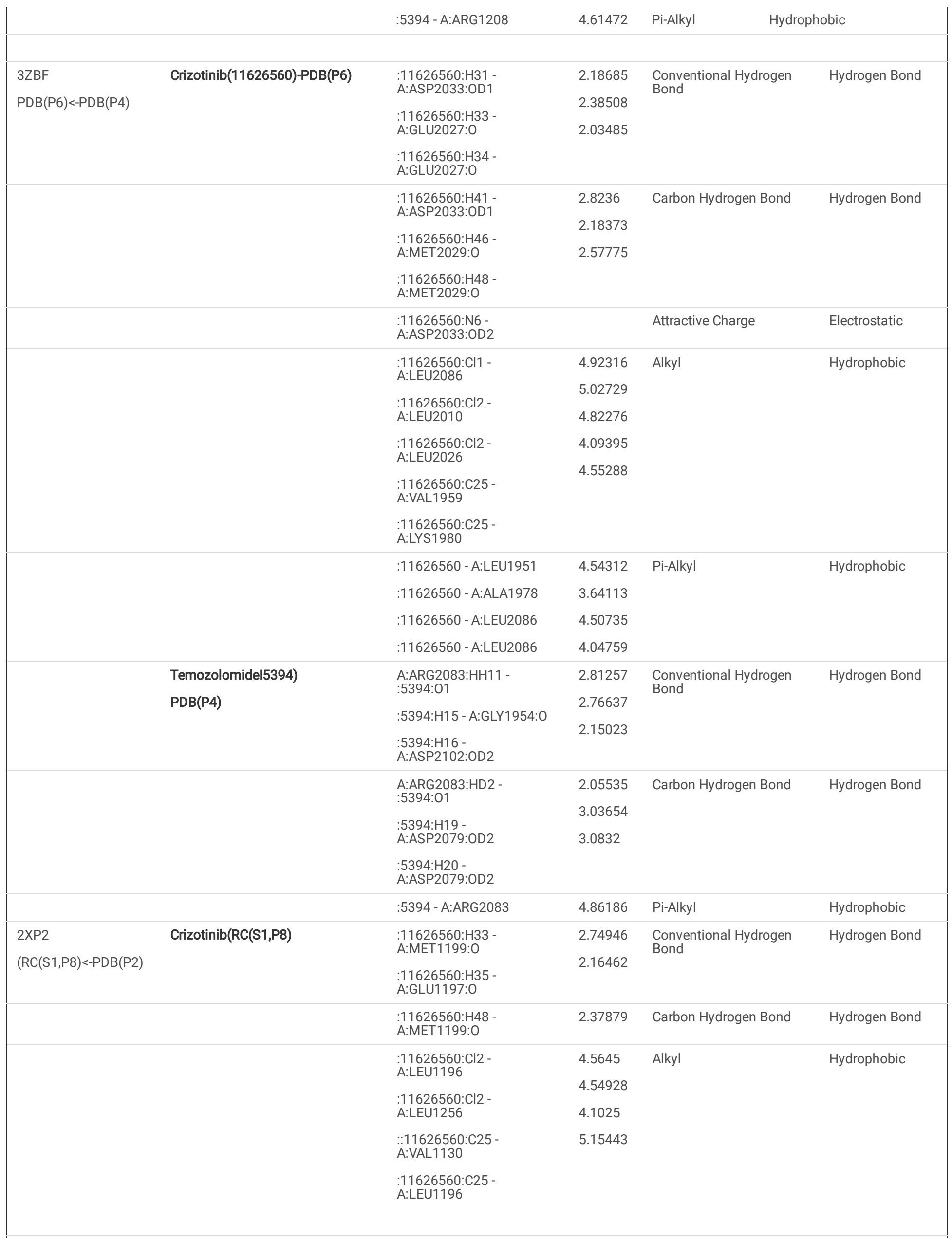




\begin{tabular}{|c|c|c|c|c|}
\hline & :11626560 - A:LEU1122 & 5.43873 & \multirow[t]{5}{*}{ Pi-Alkyle } & \multirow[t]{5}{*}{ Hydrophobic } \\
\hline & :11626560 - A:ALA1148 & 4.62228 & & \\
\hline & :11626560 - A:LEU1256 & 4.3131 & & \\
\hline & :11626560 - A:LEU1256 & 4.08598 & & \\
\hline & \multicolumn{2}{|l|}{$:$} & & \\
\hline & $\begin{array}{l}\text { :11626560:H32 - } \\
\text { A:GLU1210:OE2 }\end{array}$ & 2.00555 & $\begin{array}{l}\text { Salt Bridge;Attractive } \\
\text { Charge }\end{array}$ & $\begin{array}{l}\text { Hydrogen } \\
\text { Bond;Electrostatic }\end{array}$ \\
\hline & 11626560:Cl2 - :5394:C13 & 4.12456 & \multirow[t]{2}{*}{ Alkyle } & \multirow[t]{2}{*}{ Hydrophobic } \\
\hline & $\begin{array}{l}: 11626560: C 25- \\
: 5394: C 13\end{array}$ & 3.36074 & & \\
\hline & 11626560 - :5394:C13 & 3.80447 & \multirow[t]{4}{*}{ Pi-Alkyl } & \multirow[t]{4}{*}{ Hydrophobic } \\
\hline & :5394 - :11626560:Cl1 & 3.9617 & & \\
\hline & :5394 - :11626560:Cl1 & 4.0158 & & \\
\hline & :5394 - :11626560:C25 & 4.86966 & & \\
\hline & :11626560 - :5394 & 3.91743 & \multirow[t]{2}{*}{ Pi-Pi Stacked } & \multirow[t]{2}{*}{ Hydrophobic } \\
\hline & :5394 - :11626560 & 5.28544 & & \\
\hline \multirow[t]{6}{*}{ Temozolomide PDB(P2) } & A:LYS1150:HZ1 - :5394:01 & 1.99751 & $\begin{array}{l}\text { Conventional Hydrogen } \\
\text { Bond }\end{array}$ & Hydrogen Bond \\
\hline & :5394:H17 - A:HIS1124:O & 2.53002 & \multirow[t]{2}{*}{ Carbon Hydrogen Bond } & \multirow[t]{2}{*}{ Hydrogen Bond } \\
\hline & $\begin{array}{l}\text { :5394:H19- } \\
\text { A:ASP1270:OD2 }\end{array}$ & 2.53636 & & \\
\hline & :5394:C13 - A:LYS1150 & 4.99937 & Alkyl & Hydrophobic \\
\hline & :5394 - A:ALA1126 & 5.14915 & \multirow[t]{2}{*}{ Pi-Alkyl } & \multirow[t]{2}{*}{ Hydrophobic } \\
\hline & :5394 - A:ALA1126 & 4.2119 & & \\
\hline
\end{tabular}

Table 4

Details of Crizotinib binded protein and their main hydrogen bond interaction residues

\begin{tabular}{|lllll|}
\hline PROTEIN & RESOLUTION & CHAIN & SEQUENCE LENGTH & KEY RESIDUE \\
\hline 2XP2 & $1.9 \AA$ & A & 327 & MET1199,GLU1197 \\
2WGJ & $2 \AA$ & A & 306 & MET1160,PRO 1158 \\
\hline 3ZBF & $2.2 \AA$ & A & 322 & MET2029,GLU2027 \\
\hline
\end{tabular}

Table 5

list of ligands with CAS number which used for the study 


\begin{tabular}{|c|c|c|c|c|c|c|c|c|}
\hline SI.NO: & Ligand Name & $\begin{array}{l}\text { CAS } \\
\text { number }\end{array}$ & $\begin{array}{l}\text { Molecular } \\
\text { formula }\end{array}$ & MW & $\log P$ & $\begin{array}{l}\text { H- } \\
\text { Bond } \\
\text { donors }\end{array}$ & $\begin{array}{l}\text { H-Bond } \\
\text { acceptors }\end{array}$ & $\begin{array}{l}\text { Chemical } \\
\text { Structure }\end{array}$ \\
\hline 1 & $\begin{array}{l}\text { Crizotinib } \\
\text { (3-[(1R)-1-(2,6- } \\
\text { dichloro-3- } \\
\text { fluorophenyl)ethox } \\
\text { y]-5-(1-piperidin-4- } \\
\text { ylpyrazol-4- } \\
\text { yl)pyridin-2-amine) }\end{array}$ & $877399-52-5$ & $\underline{\mathrm{C}_{21} \mathrm{H}_{22} \mathrm{Cl}_{2} \mathrm{FN}_{5} \mathrm{O}}$ & $450.3 \mathrm{~g} / \mathrm{mol}$ & 3.7 & 2 & 6 & \\
\hline 2 & $\begin{array}{l}\text { Temozolomide } \\
\text { (3-methyl-4- } \\
\text { oxoimidazo[5,1- } \\
\text { d } 11,2,3,5] \text { tetrazine- } \\
\text { 8-carboxamide) }\end{array}$ & $85622-93-1$ & $\underline{\mathrm{C}_{6} \mathrm{H}_{6} \mathrm{~N}_{6} \mathrm{O}_{2}}$ & $194.15 \mathrm{~g} / \mathrm{mol}$ & -1.1 & 1 & 5 & \\
\hline
\end{tabular}

\section{Figures}
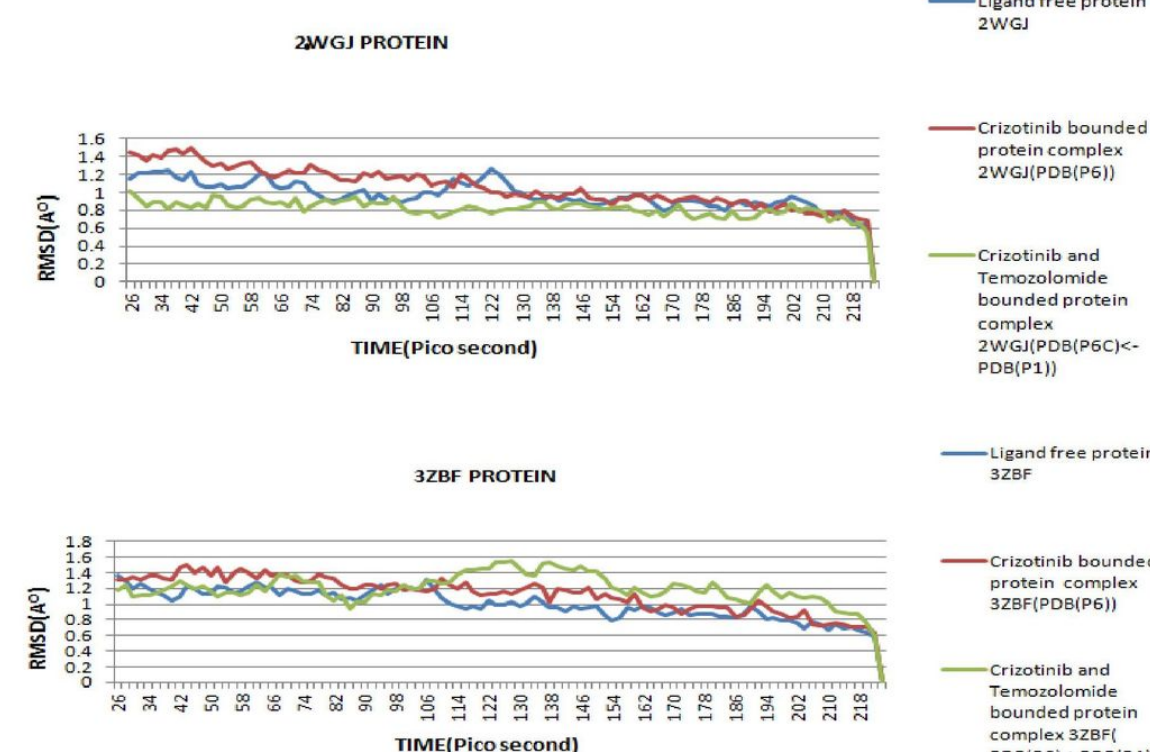

Ligand free protein
3ZBF

Crizotinib bounded protein complex ZZBF(PDB(P6))

Crizotinib and Temozolomide bounded protein complex $3 Z B F($
$P D B(P 6)<-P D B(P 4)$

2XP2 PROTEIN Ligand free protein
2XP2
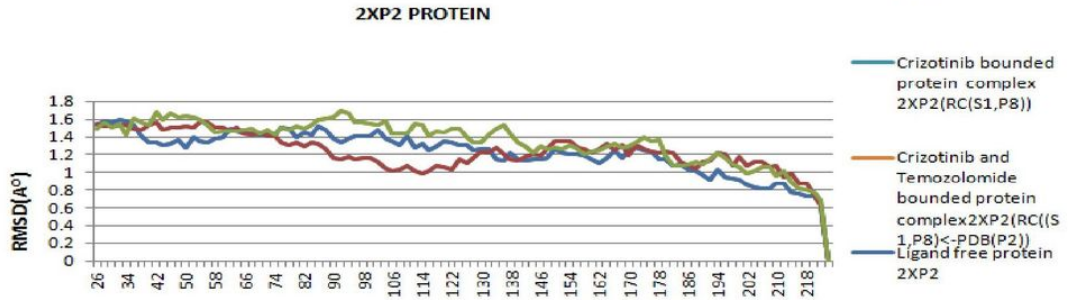

TIME(Pico second)

Figure 1

RMSD graph of single and combination drug complexes of C-MET, C-ROS1 and ALK protein 

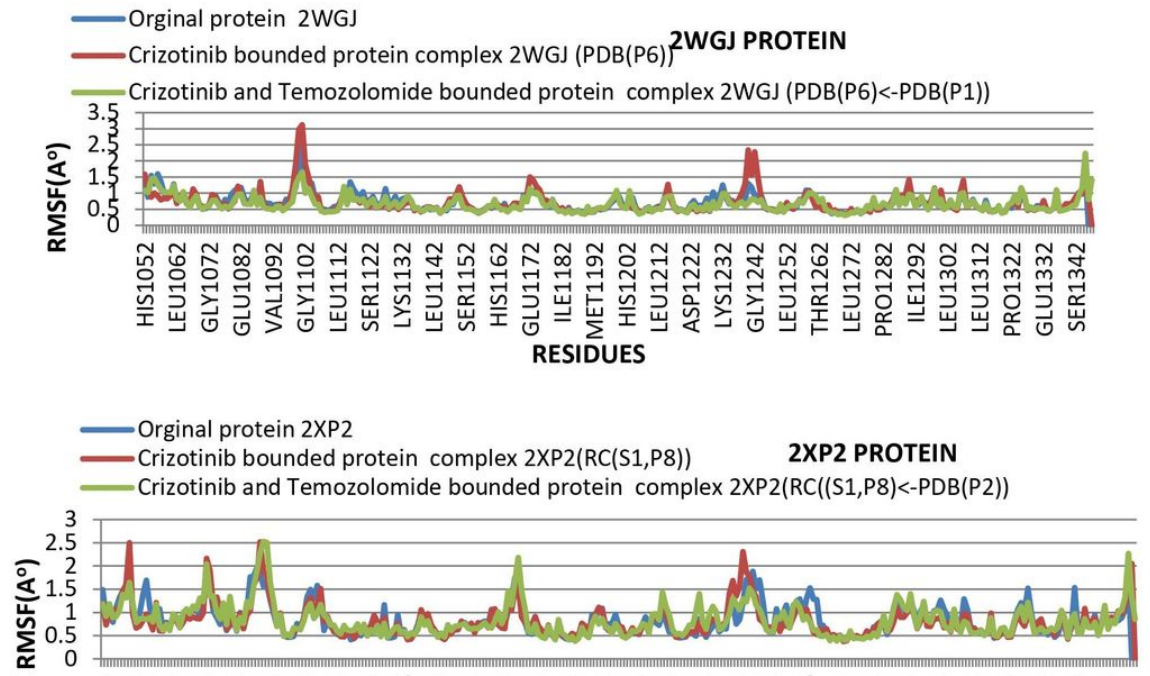

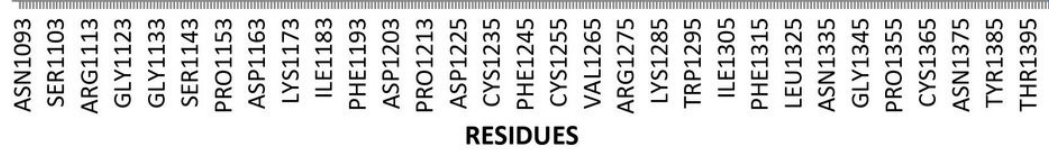

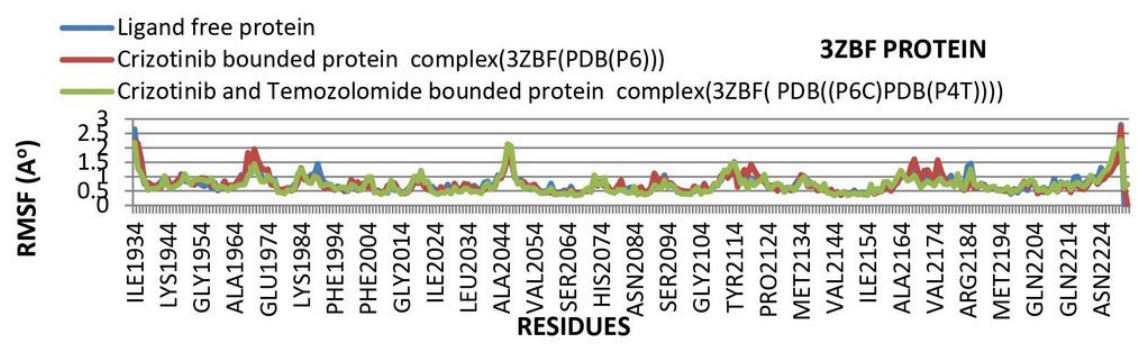

Figure 2

RMSF graph of single and combination drug complexes of C-MET, C-ROS1 and ALK protein

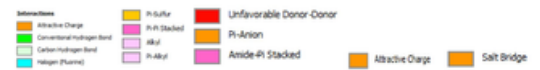

a) $2 \mathrm{WGJ}(\mathrm{PDB}(\mathrm{P})<-\mathrm{PDB}(\mathrm{P} 1))$, combination drug complex of Ciroxotinib and

Temozolomide drug with C-MET protein
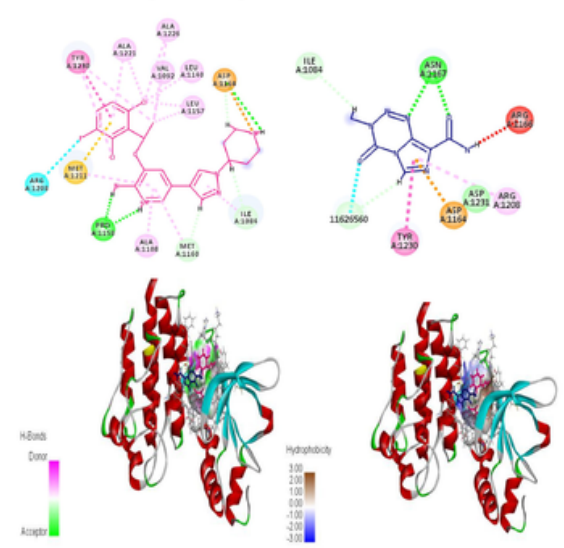
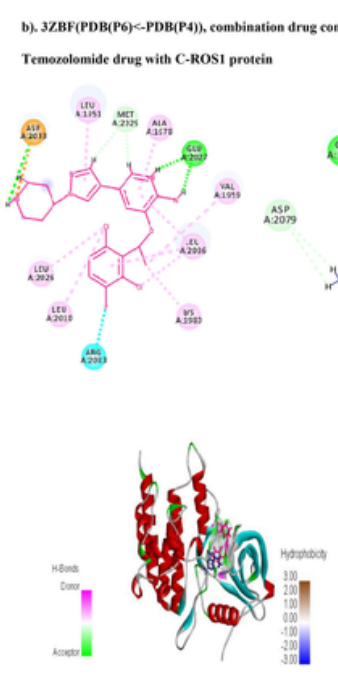

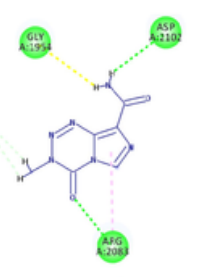

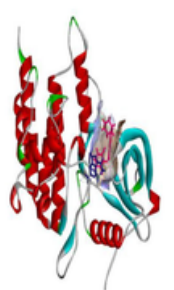

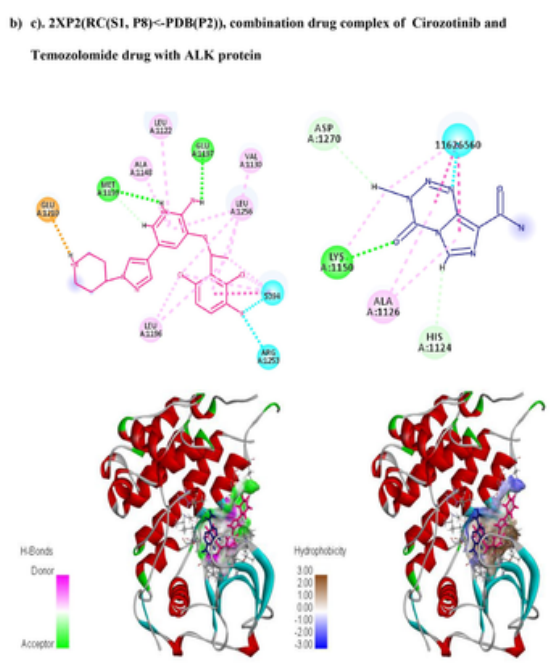

Figure 3

$(\mathbf{a}, \mathbf{b}, \mathbf{c}): 2 \mathrm{D}$ and 3D structures of combination drug complexes of Crizotinib and Temozolomide bounded with C-MET, C-ROS1 and ALK proteins. 
Each color in the square box indicates the type of interactions obtained between the drugs and amino acid residues at each protein's binding site, shown in the 2D diagram. The 3D diagram shows the hydrogen bond and hydrophobic interaction of Crizotinib and Temozolomide drug at the binding sites of each protein (Magenta color indicates Crizotinib drug, and dark blue indicate Temozolomide drug).

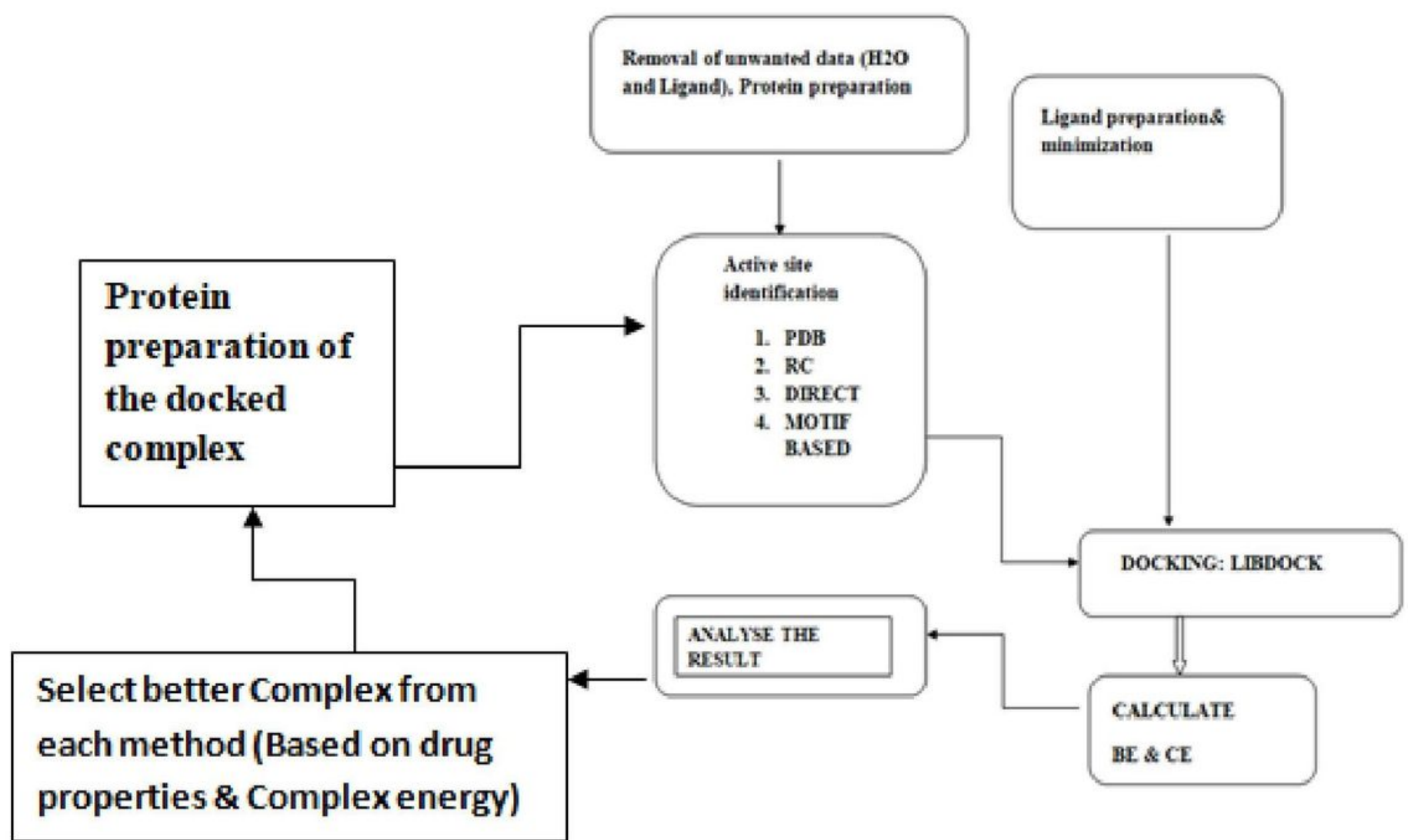

Figure 4

The pipeline used in the docking study of combination drug CRizotinib and Temozolomide with

C-MET,C-ROS1 and ALK proteins.

\section{Supplementary Files}

This is a list of supplementary files associated with this preprint. Click to download.

- supplementaryfile.docx 